\title{
Long-Term Changes in the Climatology of Transient Inverted Troughs over the North American Monsoon Region and Their Effects on Precipitation
}

\author{
TIMOTHY M. LAHMERS AND CHRISTOPHER L. CASTRO \\ Department of Atmospheric Sciences, University of Arizona, Tucson, Arizona \\ DAVID K. ADAMS \\ Centro de Ciencias de la Atmósfera, Universidad Nacional Autónoma \\ de México, Mexico City, Mexico \\ YOLANDE L. SERRA \\ Joint Institute for Study of the Atmosphere and Ocean, University of \\ Washington, Seattle, Washington \\ JOHN J. BROST \\ National Weather Service, Southern Region Headquarters, Fort Worth, Texas \\ THANG LUONG \\ Centro de Ciencias de la Atmósfera, Universidad Nacional Autónoma \\ de México, Mexico City, Mexico
}

(Manuscript received 15 October 2015, in final form 15 April 2016)

\begin{abstract}
Transient inverted troughs (IVs) are a trigger for severe weather during the North American monsoon (NAM) in the southwest contiguous United States (CONUS) and northwest Mexico. These upper-tropospheric disturbances enhance the synoptic-scale and mesoscale environment for organized convection, increasing the chances for microbursts, straight-line winds, blowing dust, and flash flooding. This work considers changes in the track density climatology of IVs between 1951 and 2010. IVs are tracked as potential vorticity (PV) anomalies on the $250-\mathrm{hPa}$ surface from a regional climate model that dynamically downscales the NCEPNCAR Reanalysis 1. Late in the NAM season, a significant increase in IV track density over the 60-yr period is observed over Southern California and western Arizona, coupled with a slight decrease over northwest Mexico. Changes in precipitation are evaluated on days when an IV is observed and days without an IV, using high-resolution model-simulated precipitation estimates and CPC gridded precipitation observations. Because of changes in the spatial distribution of IVs during the 1951-2010 analysis period, which are associated with a strengthening of the monsoon ridge, it is suggested that IVs have played a lesser role in the initiation and organization of monsoon convection in the southwest CONUS during recent warm seasons.
\end{abstract}

Supplemental information related to this paper is available at the Journals Online website: http://dx.doi.org/10.1175/JCLI-D-150726.s1.

Corresponding author address: Timothy Lahmers, Department of Atmospheric Sciences, University of Arizona, 1118 East Fourth St., PAS 518, Tucson, Arizona 85721.

E-mail: timothylahmers@email.arizona.edu

\section{Introduction}

The North American monsoon (NAM) impacts the southwest contiguous United States (CONUS) as well as northwest Mexico (Douglas et al. 1993; Adams and Comrie 1997) between late June and mid-September. The NAM is the time of the year the region experiences the majority of thunderstorms and severe weather, (e.g., Maddox et al. 1995; McCollum et al. 1995). This study 


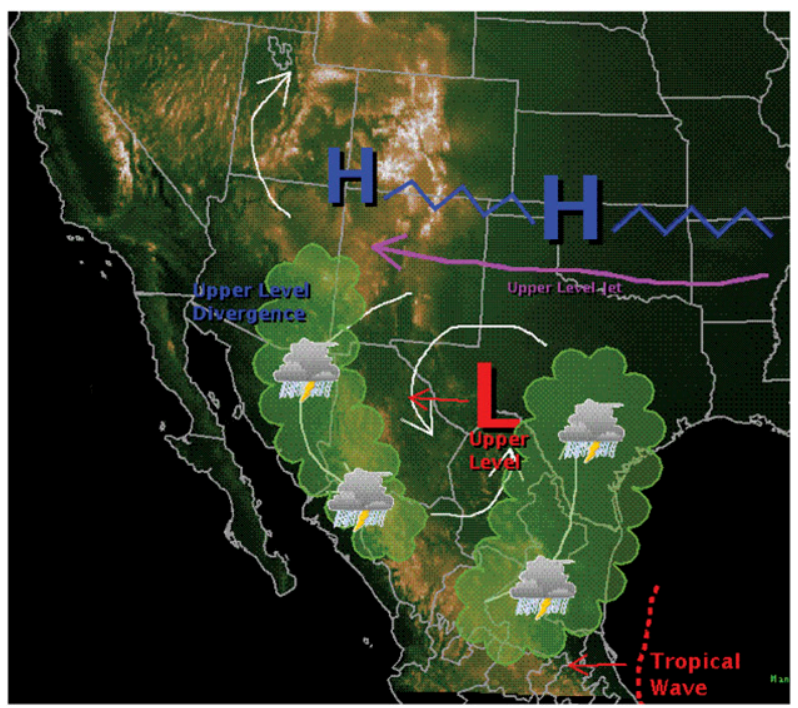

FIG. 1. Idealized illustration of an inverted trough and its meteorological effects. This figure is similar to Fig. 2 of Pytlak et al. (2005).

assesses long-term changes in organized convection throughout the NAM region in relation to the behavior of transient inverted troughs (IVs) from 1951 to 2010. IVs enhance the diurnally forced convection that forms over the high terrain, allowing it to organize and propagate toward the low deserts of Arizona (e.g., Pytlak et al. 2005; Bieda et al. 2009; Finch and Johnson 2010; Newman and Johnson 2012; Seastrand et al. 2015).

IVs that affect the NAM region often form over the Gulf of Mexico. Pytlak et al. (2005) note that these features also form over the Mississippi Valley from midlatitude fronts before propagating westward in the easterly flow south of the quasistationary uppertropospheric monsoon anticyclone (e.g., Douglas et al. 1993). The exact roles of synoptic and mesoscale processes associated with IVs and convective organization are not entirely understood. Pytlak et al. (2005) describe these features as easterly moving upper-tropospheric cyclonic disturbances that are associated with quasigeostrophic vertical motion (e.g., Kelly and Mock 1982; Whitfield and Lyons 1992). Positive differential vorticity advection can occur on either flank of an IV, depending on propagation speed (e.g., Bieda et al. 2009; Pytlak et al. 2005). Divergence aloft on the west flank of an IV can also lead to ascent and destabilization (Pytlak et al. 2005). These processes are shown in Fig. 1, modified from Pytlak et al. (2005). Finch and Johnson (2010) examine the dynamics of one IV case, where synopticscale forcing was limited, and suggest that these features influence severe weather by the enhancement of uppertropospheric wind shear, in contrast to the findings of
Pytlak et al. (2005). When an IV is in the region, storms move off the mountains into the lower terrain rather than dissipating (Finch and Johnson 2010; Newman and Johnson 2012). Seastrand et al. (2015) find similar results examining the wind fields associated with the IVs present in one of two primary modes of NAM rainfall variability, based on an 8-yr June-September climatology. Bosart et al. (2011) examined the role of potential vorticity disturbances (PVDs) on convection in the NAM region. In one case of a mesoscale convective system (MCS) that impacted southern Arizona, they show that an easterly PVD, with an IV-like structure that formed over the eastern CONUS, was associated with synopticscale forcing and enhanced surface to $6-\mathrm{km}$ wind shear in the area where the MCS formed. Besides IVs, the position of the 500-hPa high pressure, or monsoon ridge, centered over the southwest CONUS during the NAM, affects precipitation throughout the region (Carleton 1987; Adams and Comrie 1997). A northward (southward) displacement of the ridge is associated with increased (decreased) precipitation over the region.

Previous studies have employed subjective criteria for identification of IVs and their impact on the NAM. Douglas and Englehart (2007) examined a climatology of IVs over the NAM region by analysis of $500-\mathrm{hPa}$ NOAA "daily weather maps" between 1967 and 2001. Since IVs and similar features are often strongest in the upper troposphere (e.g., Bieda et al. 2009), the climatology described by Douglas and Englehart (2007) may have missed weaker upper-tropospheric IV features that would not have been detected in the lower troposphere. These authors note that easterly waves, which have their strongest signature in the lower troposphere and are unrelated to IVs but are visible at $500 \mathrm{hPa}$, are included in their analysis. Bieda et al. (2009) manually tracked IVs from 1980 to 2002 by detecting IV features for each day of the monsoon season from analysis of North American Regional Reanalysis (NARR) geopotential heights at $250,300,500$, and $700 \mathrm{hPa}$. IV centers were located using vorticity and GOES water vapor imagery to produce a track density climatology. Bieda et al (2009) note spatial increases, particularly in the low deserts, of cloud-to-ground lightning and precipitation on designated "trough days" during their analysis period (1980-2002), showing the role of IVs in facilitating organized convection.

Given that IVs can facilitate severe weather, the question of how NAM severe weather has changed during the reanalysis record, and how that may be related to IVs, has not been analyzed. Literature suggests that extreme weather events will increase in frequency due to increasing mean temperature and atmospheric water vapor capacity (e.g., Meehl et al. 2000; Muller 

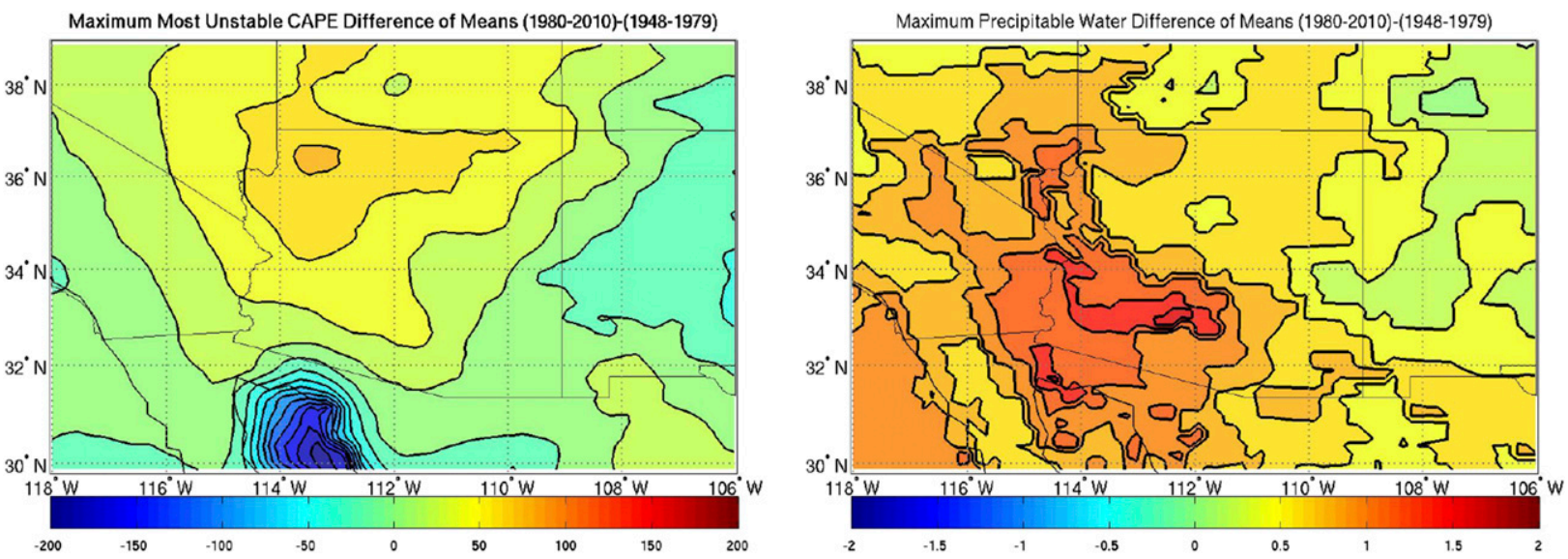

FIG. 2. (left) Most unstable CAPE (MUCAPE; $\mathrm{J} \mathrm{kg}^{-1}$ ) and (right) PW (mm) trends from WRF downscaled NCEP-NCAR Reanalysis I between the periods 1950-79 and 1980-2010. Months considered are July and August. This figure is adapted from Jares et al. (2014).

et al. 2011; O'Gorman 2012), per the exponential relationship between saturation vapor pressure and temperature given by the Clausius-Clapeyron relation. Data from observational records indicate this may be happening within the United States and globally (e.g., Min et al. 2011; Groisman et al. 2005; Karl and Knight 1998). Jares et al. (2014) suggest that convective available potential energy (CAPE) (e.g., Moncrieff and Miller 1976) and integrated precipitable water (PW) (e.g., Lu et al. 2009) have significantly increased throughout the southwest CONUS during the NAM season in dynamically downscaled reanalysis from 1948 to 2010 (Fig. 2). These trends are examined from observations in section $3 \mathrm{a}$ of the present study, using the methods of Adams and Souza (2009), who showed that most unstable CAPE is the thermodynamic quantity most closely related to convective precipitation in the southwest CONUS.

In this study, we employ a regional climate model (RCM) forced by a long-term retrospective global atmospheric reanalysis to analyze IV track density trends during 1951-2010. The track density climatology from reanalysis forcing is compared to equivalent analysis from the RCM. Using an objective tracking technique and the RCM dataset, this work builds on the findings of Bieda et al. (2009) to examine IV climatology. Given recent work suggesting that the thermodynamic environment throughout the NAM region is becoming more favorable for convection (Jares et al. 2014), effects of dynamic changes (i.e., IV track density climatology) are likely superimposed on these known processes. Thermodynamic changes to the monsoon convective environment are considered for time periods when the number of IVs is not significantly changing and on days without IVs. Otherwise, both the impacts of IVs and thermodynamic impacts on convection are examined.
Analysis of other dynamic processes associated with the NAM, such as tropical cyclones (e.g., Wood and Ritchie 2013; Ritchie et al. 2011; Corbosiero et al. 2009), is beyond the scope of this paper.

In what follows, we elucidate the methodology in section 2 and present the IV climatology and its impacts on local weather patterns in section 3 . This includes analysis of the physical mechanisms behind observed changes and an assessment of the IV climatology from the RCM and global reanalysis datasets. A discussion of the effects of IV changes on modeled and observed precipitation is presented in section 4 . Conclusions are presented in section 5 .

\section{Data and methods}

\section{a. Dynamical downscaling of NCEP reanalysis with the WRF Model}

This study uses the NCEP-NCAR global reanalysis (Kalnay et al. 1996) dataset for the period 1951-2010 to force the Advanced Research Weather Research and Forecasting (WRF) Model (ARW) (Skamarock et al. 2008). This RCM simulation, which is nominally the same as the one described in Castro et al. (2012), has a grid spacing of $35 \mathrm{~km}$ and a domain that covers the CONUS and Mexico (Fig. 3). Model parameterization information is shown in Table 1. Spectral nudging is used to preserve the model representation of large-scale features from the reanalysis data (e.g., von Storch et al. 2000; Castro et al. 2005; Miguez-Macho et al. 2005; Rockel et al. 2008). Use of a higher-resolution RCM is able to add value in the representation of the NAM in aspects like the diurnal cycle of convection (Castro et al. 2007a) and interannual precipitation variability (Castro et al. 2007b). The 35-km RCM adds value to the IV track density climatology (see next section); however, its 

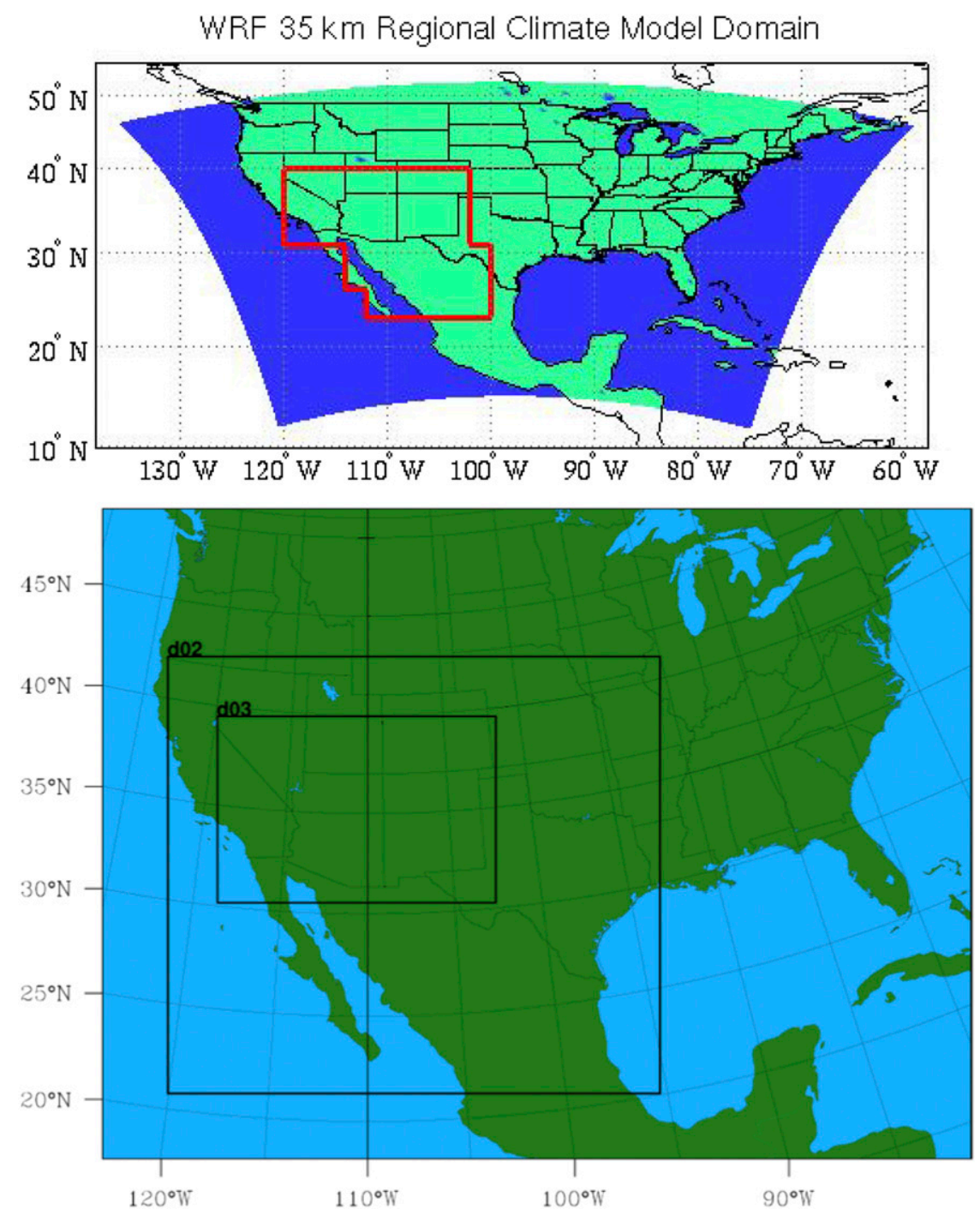

FIG. 3. (top) The 60-yr WRF regional climate model domain is shown as a land/sea mask. The IV analysis region (IVAR) domain, used for selecting trough days, is delineated with a heavy red line. (bottom) Nested grids for NWP-type simulations. Grid sizes are $35 \mathrm{~km}$ (RCM grid) for domain 1 (D01), $10 \mathrm{~km}$ for D02, and $2.5 \mathrm{~km}$ for D03.

reliance on a cumulus parameterization makes its precipitation outputs inadequate for impacts assessment because of the poor representation of organized convection. A convective-permitting scale (horizontal grid spacing less than or equal to $5 \mathrm{~km}$ ) is required for atmospheric simulations to resolve MCSs in the NAM region (e.g., Janowiak et al. 2007; Li et al. 2008). Precipitation trends from convective-permitting $2.5-\mathrm{km}$ grid spacing NWP-type simulations, which utilize the WRF downscaled reanalysis as boundary forcing, are considered. Following the methodology proposed by Adams and Souza (2009), these convective-permitting simulations are of the most thermodynamically favorable days for the Southwest as a whole during the warm season
[June-September (JJAS)], based on days with the highest values (top 20\%) of CAPE and PW (Jares et al. 2014) from the $35-\mathrm{km}$ RCM simulation, during the years 1951-70 and 1991-2010. However, these are only associated with the presence of an IV that can affect the NAM region $12 \%-21 \%$ of the time near the peak of the monsoon season. The specific simulation procedure to produce these data is as follows, consistent with Castro et al. (2015). High-resolution NWP-type simulations are run from 0600 UTC for a selected convective day (defined in section 2d) until 1200 UTC the following day. The $35-\mathrm{km} \mathrm{RCM}$ is used to force $10-\mathrm{km}$ one-way nested simulations, which subsequently force the one-way nested 2.5-km simulations (Fig. 3). 
TABLE 1. WRF-ARW parameterization settings for NWP-type simulations of thermodynamically favorable convective days. Note that a cumulus parameterization is not used for model domain 3 . WRF-ARW namelist options for selected schemes are shown in parentheses.

\begin{tabular}{ll}
\hline \hline \multicolumn{1}{c}{ Physics module } & \multicolumn{1}{c}{ Scheme (option) } \\
\hline $\begin{array}{l}\text { Microphysics } \\
\text { Longwave radiation }\end{array}$ & New Thompson et al. (8) \\
& New Rapid Radiative Transfer \\
Model (4) \\
Shortwave radiation & New Rapid Radiative Transfer \\
& Model (4) \\
Surface layer & Eta similarity (2) \\
Land surface & Noah-MP (4) \\
Urban surfaces & Urban canopy model (1) \\
Planetary boundary layer & Mellor-Yamada-Janjic (2) \\
Cumulus parameterization & Kain-Fritsch (1) \\
\hline
\end{tabular}

\section{b. Data processing}

The RCM, with 3-h temporal resolution, is regridded onto a latitude/longitude grid, so that it is compatible with the tracking system. The NCEP-NCAR reanalysis product is regridded from its native grid to the same latitude/longitude grid used to analyze the RCM, to ensure consistency. Because both model datasets are regridded onto the same grid, the tracking methods for the RCM and NCEP-NCAR reanalysis are identical, except that the reanalysis has 6-h temporal resolution. IVs are tracked as normalized potential vorticity (PV) anomalies at $250 \mathrm{hPa}$. Detection of IVs through PV on constant pressure surfaces is consistent with National Weather Service (NWS) practices (J. Meyer, NWS Tucson, 2015, personal communication). Use of PV to locate IVs is similar to the work of Bosart et al. (2011), who used dynamic tropopause surfaces to locate PVDs. Data from the 1951-2010 RCM dataset between 0000 UTC 27 May and 2100 UTC 5 October are extracted. This allows for the construction of a PV climatology, encompassing 0000 UTC 1 June to 2100 UTC 30 September. This climatology consists of a 10-day running unweighted PV mean and standard deviation at every point on the analysis grid for all time steps, allowing for the computation of normalized PV anomalies from the regridded $\mathrm{PV}$ data. The final product is a value equivalent to the difference between the modeled PV at any grid point and its climatological mean, divided by its standard deviation (i.e., a $Z$ score). Since IVs are associated with lower PV values compared to midlatitude disturbances, they would be difficult to track without normalization, due to the greater midlatitude PV.

\section{c. IV feature tracking}

Each IV feature is tracked as a 250 -hPa normalized PV relative maximum. This is justified by Finch and
Johnson (2010) and Pytlak et al. (2005), who both suggest that IV features are strongest in the upper troposphere. The tracking algorithm can locate moving disturbances on a spherical grid through variables such as relative vorticity. The algorithm is effective for distinguishing 850-hPa relative vorticity disturbances in the tropics and midlatitudes (Hodges 1995). Optimization of the track locations is used to ensure accurate output, and the tracking code allows the user to define tracking criteria for a variety of meteorological situations (Hodges 1999). This code can detect 850-hPa monsoon disturbances over the Indian Ocean from relative vorticity, which may be challenging to locate by objective means given the spatial variability of this quantity (Hodges 1999). The code has been used for tropical easterly waves over the tropical Atlantic and east Pacific Oceans (e.g., Thorncroft and Hodges 2001; Serra et al. 2010) and for winter storms in the Northern Hemisphere (e.g., Hoskins and Hodges 2002).

Each PV anomaly must contain at least eight grid points ( $\sim 0.57$ decimal degrees squared) with values that exceed 2 standard deviations to be tracked, which eliminates weaker disturbances. Features are assumed to move at near $3 \mathrm{~m} \mathrm{~s}^{-1}$, as large-scale easterly flow on the south side of the monsoon ridge is generally weak. The normalized PV data are smoothed with four iterations of a nine-point smoothing algorithm, eliminating noise in the dataset. Features lasting less than $21 \mathrm{~h}$ (eight time steps) are removed to eliminate disturbances associated with diurnal convection. Since IVs generally propagate westward, all easterly disturbances and only westerly disturbances that have a southerly component greater than or equal to the westerly component are analyzed. These features are kept because IVs often recurve to the north around the monsoon high into the westerly regime. All other features are removed, eliminating midlatitude disturbances from analysis. Only features within the region $16^{\circ}-40^{\circ} \mathrm{N}, 120^{\circ}-90^{\circ} \mathrm{W}$ are tracked. This region is equivalent to the North American Monsoon Experiment (NAME) Tier II region (Higgins et al. 2006), except the lower boundary is farther north due to the limits of the RCM domain.

Features are tracked through the following 33-day time intervals: 4 June-6 July, 19 June-21 July, 4 July5 August, 19 July-20 August, 3 August-4 September, and 18 August- 19 September. These intervals are nearly equivalent to the analysis periods of IV track density used by Bieda et al. (2009). To assess IV track density trends, two 30-yr track density climatology datasets are computed (1951-80 and 1981-2010) for each time interval described above. To ensure that these results are consistent throughout the 60 -yr dataset, similar methods 
are used for analysis of overlapping 30- and 40-yr time periods within this dataset (see section 3c). Track density is computed with a power-based kernel smoothing technique described by Hodges (1996) and normalized by the number of seasons considered. The final track density grids have $0.3804^{\circ}$ spatial resolution. The track density data considered for analysis are based on the point density of tracks from model time steps, with no interpolation between these times. The track density considered for this study is equivalent to "feature density," noted by Hodges (1996), so these plots depict the number feature points per 5-deg spherical cap per subseason (Figs. 4 and 5). The average intensity of tracked IV features (in units of normalized PV) is computed using similar methods as those used to compute track density. Analysis of track density plots in the next section shows relatively high density $(\sim 30$ features per subseason) because one IV may be associated with multiple feature points in an area.

\section{d. Statistical methods}

Monte Carlo methods are used to assess the statistical significance of differences between the early and late period track densities. A permutation approach is used to randomize the year of the track dataset. The $601-\mathrm{yr}$ track outputs for each subsection of the monsoon season are randomized, and two sets of 30 mutually exclusive track files are used to compute track density. The difference between these track densities is computed at every grid point. This process is repeated 500 times to generate a null distribution of track density differences. The 5th and 95th percentiles of this null distribution are used to assess the statistical significance of the difference of track density means between the early and late periods in the original dataset. Similar methods are employed for computing track density trends from the overlapping 30- and 40-yr datasets.

One of the complications of using downscaled NCEPNCAR Reanalysis I data is the introduction of satellite and aircraft data in 1979. Ebisuzaki and Kistler (2000) suggest that the addition of these data into a reanalysis product may introduce bias over the oceans where radiosonde data are sparse, particularly in the tropics. This would make IV track density trends over the eastern Pacific questionable, even if physically significant changes occurred over North America. To assess IV trends and their physical significance, an IV analysis region (IVAR) encompassing the southwest CONUS and northwest Mexico is designated 1) to eliminate disturbances over the Pacific Ocean that may be affected by the addition of satellite and aircraft data and 2) to isolate IV features that have the most impact on NAM precipitation.
The IVAR (Fig. 3) includes the domain encompassing $31^{\circ}-40^{\circ} \mathrm{N}$ and $120^{\circ}-102^{\circ} \mathrm{W}$, which covers the southwest CONUS from extreme western Texas to Southern California. This part of the IVAR extends to the northern and western edges of the NAME Tier II region. The eastern boundary is justified by the fact that features centered farther east (assuming a 500-km radius), would only influence convection in eastern and central New Mexico and Colorado. Farther south, the IVAR spans $23^{\circ}-31^{\circ} \mathrm{N}$ and $114^{\circ}-100^{\circ} \mathrm{W}$, which includes IV features that can trigger MCSs in northwest Mexico. The eastern boundary for this region is extended east since it is approximately $500 \mathrm{~km}$ away from the southern end of the Sierra Madre Occidental, a mountain range in northwest Mexico where NAM convection often forms. The southern boundary of the IVAR extends to the tip of the Baja Peninsula, as IVs in this region may contribute to the formation of gulf surges that can advect moisture into the southwest CONUS (e.g., Schiffer and Nesbitt 2012). The area including $23^{\circ}-26^{\circ} \mathrm{N}$ and $114^{\circ}-112^{\circ} \mathrm{W}$ is eliminated from the IVAR because it encompasses areas over the Pacific Ocean, which are prone to reanalysis errors (e.g., Ebisuzaki and Kistler 2000). A field significance test (Livezey and Chen 1983) is performed on the track density difference composites within the IVAR, using the same 500 random samples noted above. The 90th percentile of this null distribution is used to assess field significance.

Precipitation changes associated with IVs from 1951 to 2010 are investigated through the division of analyzed days into "trough days" and "no-trough days." Any convective day, including the 1200 UTC through 0900 UTC (the following day) model times, when an IV feature is detected by the tracking system within the IVAR during any analyzed time step is considered a trough day. A convective day encompasses the entire diurnal convective cycle, regardless of whether convection or precipitation forms, with a maximum in storm coverage during the afternoon or early evening. Ending a convective day at 0900 UTC ensures no overlap between days. All other convective days are considered no-trough days. Note that since each 33-day interval starts and ends at 0000 and 2100 UTC, respectively, 32 convective days are analyzed from the intervals noted in section $2 c$, where the earliest interval encompasses the convective days from 4 June to 5 July.

To account for the effects of extreme precipitation caused by tropical storms in the NAM region (i.e., Corbosiero et al. 2009; Ritchie et al. 2011), tropical storm events are removed from analysis. Tracks of all tropical disturbances from the HURDAT2 dataset (Landsea and Franklin 2013) are used to flag tropical 

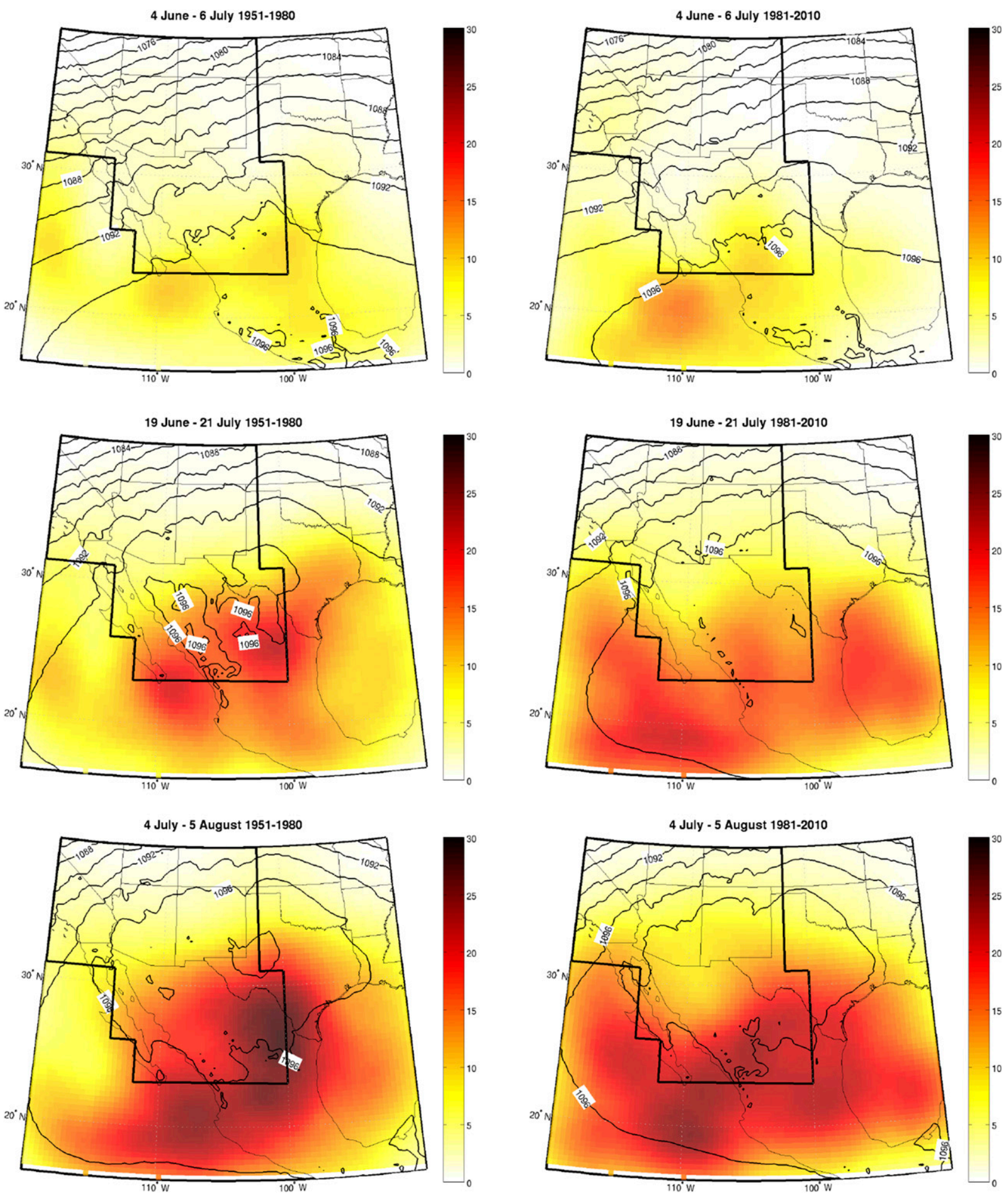

FIG. 4. (left) 1951-80 and (right) 1981-2010 track density for (top) 4 Jun-6 Jul, (middle) 19 Jun-21 Jul, and (bottom) 4 Jul-5 Aug; 250-hPa geopotential heights are shown with black contours. The IVAR is shown with a heavy black line.

cyclone events. Any convective day where a tropical system is detected in the IVAR region is removed from analysis. Thus, analysis of precipitation and meteorological trends discussed below excludes tropical cyclone days. The number of identified tropical cyclone days, trough days, and no-trough days for each analysis interval is shown in Table 2. A majority of the removed tropical cyclone days are late in the NAM season, while 

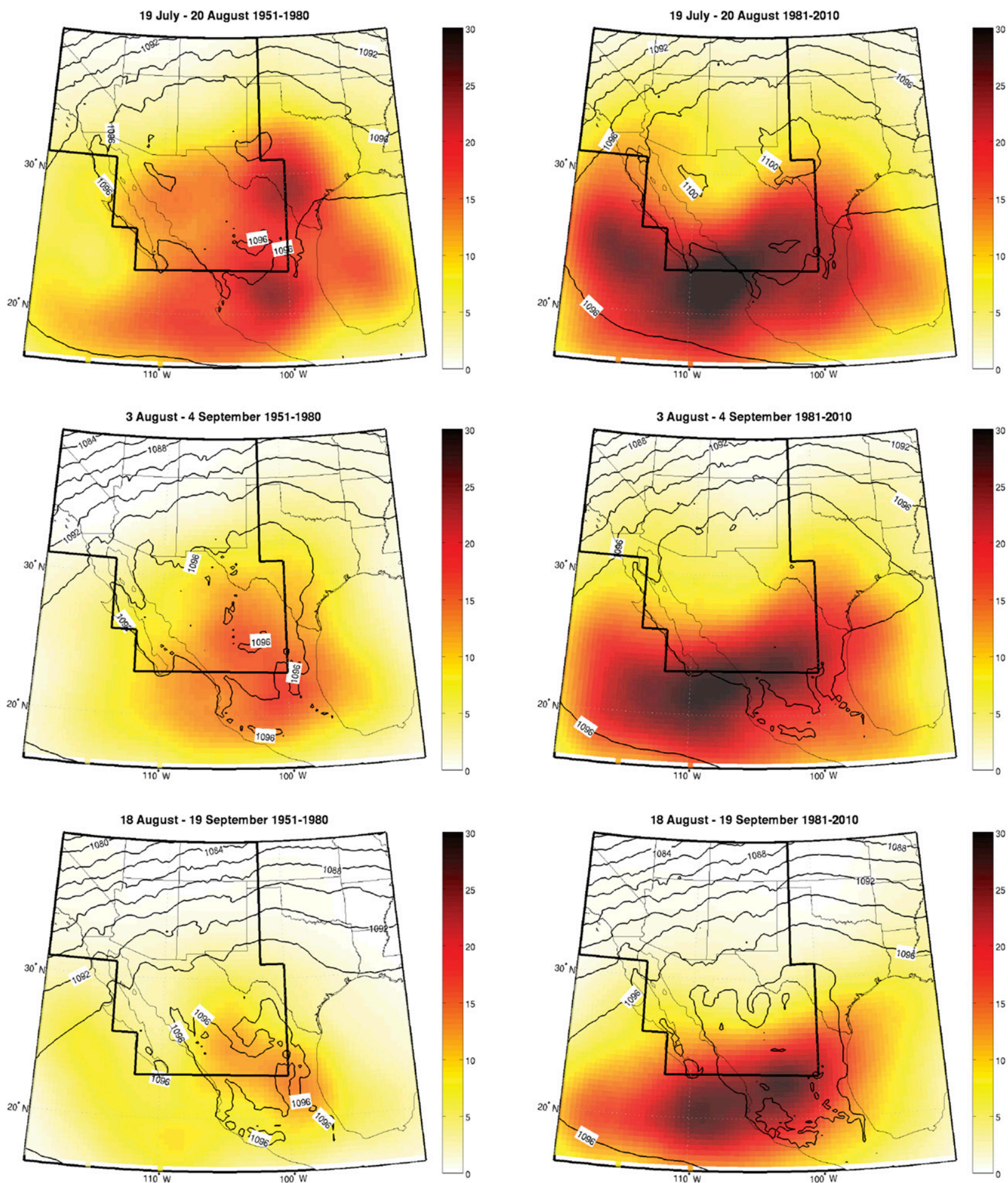

FIG. 5. As in Fig. 4, but for (top) 19 Jul-20 Aug, (middle) 3 Aug-4 Sep, and (bottom) 18 Aug-19 Sep.

trough days peak near the middle of the season. This seasonality of IVs and tropical cyclones is consistent with Bieda et al. (2009) and $\mathrm{Hu}$ and Dominguez (2015), respectively. Table 2 also includes the count of thermodynamically favorable trough days and no-trough days near the peak of the NAM season that were identified following the methods of Jares et al. (2014). The high-resolution NWP-type simulations described in the previous section are of these selected convective days. 
TABLE 2. Observed numbers of (from left to right) tropical cyclone (TC) days (removed from analysis), no-trough days, trough days, notrough days with favorable thermodynamics, and trough days with favorable thermodynamics. TC days refer to days with a tropical feature entering the IVAR during any time of the convective day. Trough days refer to non-TC convective days with an IV reaching the IVAR region, and no-trough days refer to all other convective days. Thermodynamically favorable convective days are selected using the methods of Jares et al. (2014) to isolate days with the highest CAPE and PW. Thermodynamically favorable convective days are only considered during the peak of the monsoon season.

\begin{tabular}{|c|c|c|c|c|c|}
\hline & TC days & No-trough days & Trough days & Favorable no-trough days & Favorable trough days \\
\hline \multicolumn{6}{|l|}{$1951-80$} \\
\hline 4 Jun-6 Jul & 6 & 901 & 53 & - & - \\
\hline 19 Jun-21 Jul & 6 & 840 & 114 & - & - \\
\hline 4 Jul-5 Aug & 4 & 781 & 175 & - & - \\
\hline 19 Jul-20 Aug & 8 & 798 & 154 & 133 & 29 \\
\hline 3 Aug-4 Sep & 17 & 856 & 87 & 115 & 21 \\
\hline 18 Aug-19 Sep & 40 & 860 & 60 & - & - \\
\hline \multicolumn{6}{|l|}{$1981-2010$} \\
\hline 4 Jun-6 Jul & 1 & 910 & 49 & - & - \\
\hline 19 Jun-21 Jul & 4 & 840 & 116 & - & - \\
\hline 4 Jul-5 Aug & 3 & 783 & 174 & - & - \\
\hline 19 Jul-20 Aug & 1 & 783 & 176 & 82 & 22 \\
\hline 3 Aug-4 Sep & 27 & 792 & 141 & 125 & 18 \\
\hline 18 Aug-19 Sep & 47 & 825 & 88 & - & - \\
\hline
\end{tabular}

Daily precipitation for trough and no-trough convective days (ending at 1200 UTC) during the early and late periods is extracted from available high-resolution NWPtype simulations forced by the RCM discussed above (see section 2a) and the CPC U.S. unified precipitation dataset from the NOAA Earth System Research Laboratory (available online from NOAA/ESRL/PSD at http://www. esrl.noaa.gov/psd/). The CPC dataset encompasses the CONUS, while the high-resolution simulations encompass the NAM region (Fig. 3). Assessments of precipitation changes use a two-tailed Student's $t$ test with $90 \%$ significance. This analysis allows precipitation trends associated with changes to dynamic forcing (i.e., trough-day composites) to be compared to precipitation trends associated with only changes to thermodynamic forcing (i.e., notrough day composites), as shown in sections $3 \mathrm{~d}$ and $3 \mathrm{e}$.

\section{Results of modeled and observed composite analysis trends}

\section{a. Observed thermodynamic trends}

To illustrate the changing thermodynamic regime of the NAM region, and therefore place the results of the present study in proper context, we compare the results of Jares et al. (2014) to CAPE and PW trends based on available radiosonde observations. Following Adams and Souza (2009), CAPE is computed through the modification of the preconvective morning sounding. This is done by employing the maximum daily surface temperature recorded and the average of the mixing ratio found in the first $75 \mathrm{hPa}$ of the sounding. A well-mixed, adiabatic layer, with this surface temperature and average mixing ratio, is then assumed up to the lifted condensation level (LCL). The moist thermodynamic path is assumed pseudoadiabatic. This surface parcel may thus be thought of as resulting in the most unstable CAPE, which Adams and Souza (2009) showed correlates most highly with precipitation. On days with more than one morning sounding (e.g., 0900 and 1500 UTC soundings), CAPE and PW from all available soundings are both averaged. Annual averages (excluding years with fewer than $67 \%$ of observations archived) of CAPE and PW are significantly increasing at nearly all sites in the region (Table 3 ), which is consistent with the findings of Jares et al. (2014).

\section{b. IV climatology and skill}

The RCM-derived IV track densities and mean 250-hPa heights for each analysis interval of the monsoon season for the 1951-80 and 1981-2010 periods are plotted in Figs. 4 and 5. Qualitatively, IV track density (particularly during the 1981-2010 period) from the RCM is similar to the manual analysis of IV track density compiled by Bieda et al. (2009, their Fig. 8), as it matches the seasonality and spatial patterns of this quantity. IV climatology in relation to the NAM ridge is consistent with Pytlak et al. (2005) (Fig. 1), as the highest track densities are found south of the climatological ridge center. By mid-June through mid-July, tracks increase in coverage, as the NAM ridge amplifies (Fig. 4), reaching a peak during the 19 July-20 August interval (Fig. 5). Tracks decrease in coverage by late August to mid-September as the ridge breaks down. During the 1951-80 period, there are fewer features over the eastern Pacific Ocean throughout the season. Analysis of 
TABLE 3. Correlation coefficients and $t$ statistics for annual average CAPE and PW (15 Jun-15 Sep) trends at selected upper air sites throughout the southwest CONUS. The years used for analysis of these trends are shown in the right column. Bold font denotes statistical significance.

\begin{tabular}{lccc}
\hline \hline Correlation coefficient & CAPE & PW & Years analyzed \\
\hline Albuquerque, NM & $\mathbf{0 . 8 5 4}$ & $\mathbf{0 . 5 9 8}$ & $1950-2014$ \\
Desert Rock, NV & $\mathbf{0 . 5 8 8}$ & $\mathbf{0 . 2 7 5}$ & $1953-2014$ \\
El Paso, TX & $\mathbf{0 . 8 9 5}$ & $\mathbf{0 . 5 1 3}$ & $1950-2014$ \\
Flagstaff, AZ & $\mathbf{0 . 4 4 1}$ & $\mathbf{0 . 4 9 0}$ & $1996-2014$ \\
San Diego, CA & - & $\mathbf{0 . 3 7 5}$ & $1956-2014$ \\
Tucson, AZ & $\mathbf{0 . 7 8 8}$ & $\mathbf{0 . 2 6 3}$ & $1952-2014$ \\
Winslow, AZ & 0.097 & 0.077 & $1961-95$ \\
& & & \\
statistic & CAPE & PW & \\
Albuquerque, NM & $\mathbf{1 3 . 0 1 3}$ & $\mathbf{5 . 9 1 9}$ & \\
Desert Rock, NV & $\mathbf{5 . 5 3 1}$ & $\mathbf{2 . 1 7 8}$ & \\
El Paso, TX & $\mathbf{1 5 . 8 0 4}$ & $\mathbf{4 . 7 0 4}$ & \\
Flagstaff, AZ & $\mathbf{2 . 0 2 8}$ & $\mathbf{2 . 3 1 9}$ & \\
San Diego, CA & - & $\mathbf{3 . 0 5 9}$ & \\
Tucson, AZ & $\mathbf{9 . 5 8 6}$ & $\mathbf{2 . 0 3 7}$ & \\
Winslow, AZ & 0.532 & 0.425 & \\
\hline
\end{tabular}

these figures shows the NAM ridge strengthened from the early to late periods, while IV coverage near the center of the ridge decreased. IV tracks for the peak of the monsoon season during the 1951-80 and 1981-2010 periods are plotted in Fig. 6. Easterly tracks are colored blue, and recurving westerly tracks are colored red. Features in the IVAR are plotted with green dots. This figure illustrates the behavior of IVs as they are advected through the region and shows the recurving of some IVs into the westerly flow regime. This figure illustrates that limiting analysis of trough days to features impacting the IVAR eliminates biases over the Pacific Ocean, while preserving IVs that may impact land.

The authors performed manual analysis on tracks during one selected season, and qualitatively compared them to those found by Bieda et al. (2009). This analysis showed that many of the stronger IVs were consistent with those found by Bieda et al. (2009); however, the RCM often missed the exact location and/or timing of specific features. This tendency of numerical models to misplace PV anomalies is a known issue faced by operational forecasters (Pytlak 2006). The authors caution that the results of Bieda et al. (2009), which were partially based on visual inspection of rotation signatures in satellite measurements, may lead to inconsistent placement of PV anomalies compared to a reanalysis product. The hit ratios for IVs detected using this objective methodological approach are presented in Table 4. IVs that are tracked at the 1200 UTC time step from the $\mathrm{RCM}$ are considered a hit if they come within a determined distance of an IV detected using the methods outlined by Bieda et al. (2009). The original dataset from
Bieda et al. (2009) is the manual analysis used in this comparison; however, years after 2002 were added using consistent methods (S. Bieda, NWS Pendleton, 2013, personal communication). Table 4 shows hit ratios of greater than $65 \%$ for much of the NAM season when moderate constraints are used. This suggests that, despite the RCM being unable to capture the precise location or timing of specific IVs, the spatial distribution of them is resolved and sufficient for this climatology.

IV track density from 1981-2010, based on raw NCEP reanalysis, is shown in Fig. 7, with the RCM 250-hPa height fields, which should match NCEP reanalysis fields because this product utilizes spectral nudging. This analysis shows limited track density throughout the region, with few IVs reaching the CONUS, suggesting that the NCEP-NCAR reanalysis is unable to resolve most IVs. Because the RCM is running at a higher resolution and is better able to resolve mesoscale processes that form and maintain PV anomalies associated with IVs, the dynamical downscaling adds considerable value to this analysis. This may indicate that WRF is creating PV anomalies or enhancing existing ones that would otherwise not be detected by the tracking algorithm. The NCEPNCAR reanalysis, and consequently the RCM, are likely affected by the limited radiosonde data over Mexico. This combination of factors would explain the tendency of the RCM to temporally and spatially misplace IVs.

\section{c. Track density trends}

IV track density changes during the 1951-2010 period and their field significance are shown in Fig. 8. For the earliest three analysis intervals during the monsoon season, track density trends are not field significant. During the early NAM season, 250-hPa heights increased throughout the domain; however, the greatest increases are northwest of the NAM ridge. Figure 8 shows track density decreases across northern Mexico during the intervals from 19 June to 21 July and from 4 July to 5 August. These changes in northeast Mexico are statistically significant between 19 June and 21 July. Other statistically significant trends that can be discerned from these plots are the increases in track density over the Pacific Ocean, possibly due to the addition of satellite data in the forcing reanalysis.

The period encompassing 19 July through 20 August is associated with a decrease in IV track density in northern Sonora, while there is a statistically significant increase farther south and west. There is a statistically significant increase in track density along the Baja Peninsula, extending into Southern California. During this interval, the greatest $250-\mathrm{hPa}$ height increases occurred near the center of the NAM ridge, where IV track density decreased. Thus, the monsoon flow regime likely 

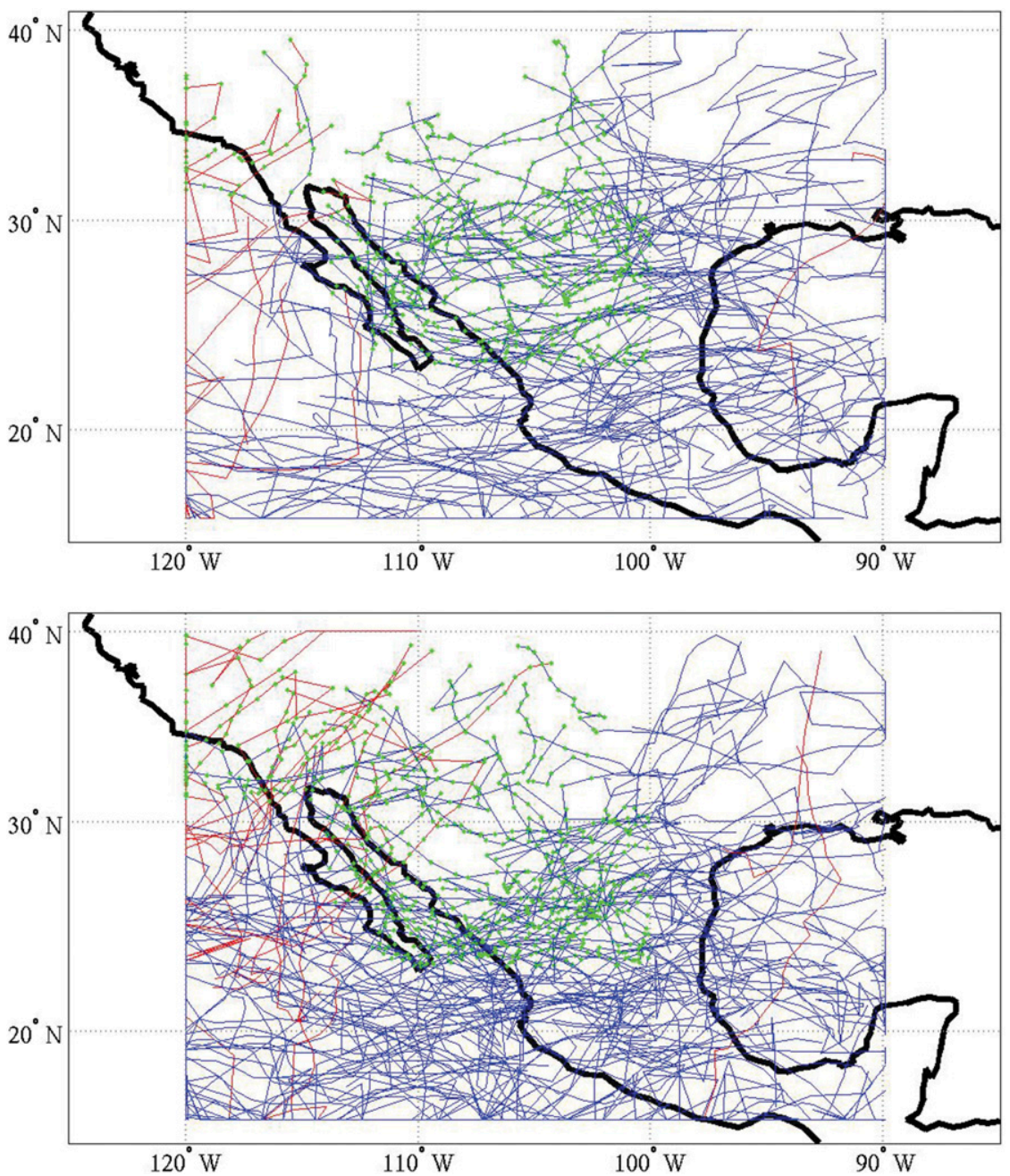

FIG. 6. (top) 1951-80 and (bottom) 1981-2010 IV tracks for 19 Jul-20 Aug. All features in the IVAR are plotted with green dots. Easterly (westerly) tracks are colored blue (red).

became more strongly anticyclonic. Lesser height increases are found south and west of the NAM ridge. This is particularly true over California, which suggests that the strengthening anticyclone may have caused the flow to become more southerly in this domain, allowing for recurvature of IV features. During the 3 August-4 September interval, the same patterns noted from the 19 July-20 August interval occurred. From 18 August to

TABLE 4. Tracked IV hit ratios (shown as percentages) for each analysis interval of the monsoon season. All IVs in the tracking domain are considered. For each interval, temporal constraints are varied by column, and spatial constraints are varied by row.

\begin{tabular}{|c|c|c|c|c|c|c|c|}
\hline 4 Jun-6 Jul & \pm 0 day & \pm 1 day & \pm 2 days & 19 Jul-20 Aug & \pm 0 day & \pm 1 day & \pm 2 days \\
\hline $5.0^{\circ}$ & 25.807 & 38.710 & 45.161 & $5.0^{\circ}$ & 36.607 & 59.821 & 63.393 \\
\hline $7.5^{\circ}$ & 45.161 & 48.387 & 54.839 & $7.5^{\circ}$ & 52.679 & 71.429 & 75.893 \\
\hline $10.0^{\circ}$ & 45.161 & 48.387 & 61.290 & $10.0^{\circ}$ & 63.393 & 75.000 & 83.036 \\
\hline 19 Jun-21 Jul & \pm 0 day & \pm 1 day & \pm 2 days & 3 Aug-4 Sep & \pm 0 day & \pm 1 day & \pm 2 days \\
\hline $5.0^{\circ}$ & 36.000 & 54.667 & 61.333 & $5.0^{\circ}$ & 41.861 & 61.628 & 65.116 \\
\hline $7.5^{\circ}$ & 64.000 & 76.000 & 81.333 & $7.5^{\circ}$ & 55.814 & 74.419 & 80.233 \\
\hline $10.0^{\circ}$ & 70.667 & 81.333 & 86.667 & $10.0^{\circ}$ & 68.605 & 76.744 & 86.047 \\
\hline 4 Jul-5 Aug & \pm 0 day & \pm 1 day & \pm 2 days & 18 Aug-19 Sep & \pm 0 day & \pm 1 day & \pm 2 days \\
\hline $5.0^{\circ}$ & 37.288 & 61.017 & 66.949 & $5.0^{\circ}$ & 37.736 & 54.717 & 60.377 \\
\hline $7.5^{\circ}$ & 61.017 & 80.509 & 83.051 & $7.5^{\circ}$ & 52.830 & 67.925 & 73.585 \\
\hline $10.0^{\circ}$ & 73.729 & 85.593 & 89.831 & $10.0^{\circ}$ & 62.264 & 69.811 & 77.359 \\
\hline
\end{tabular}



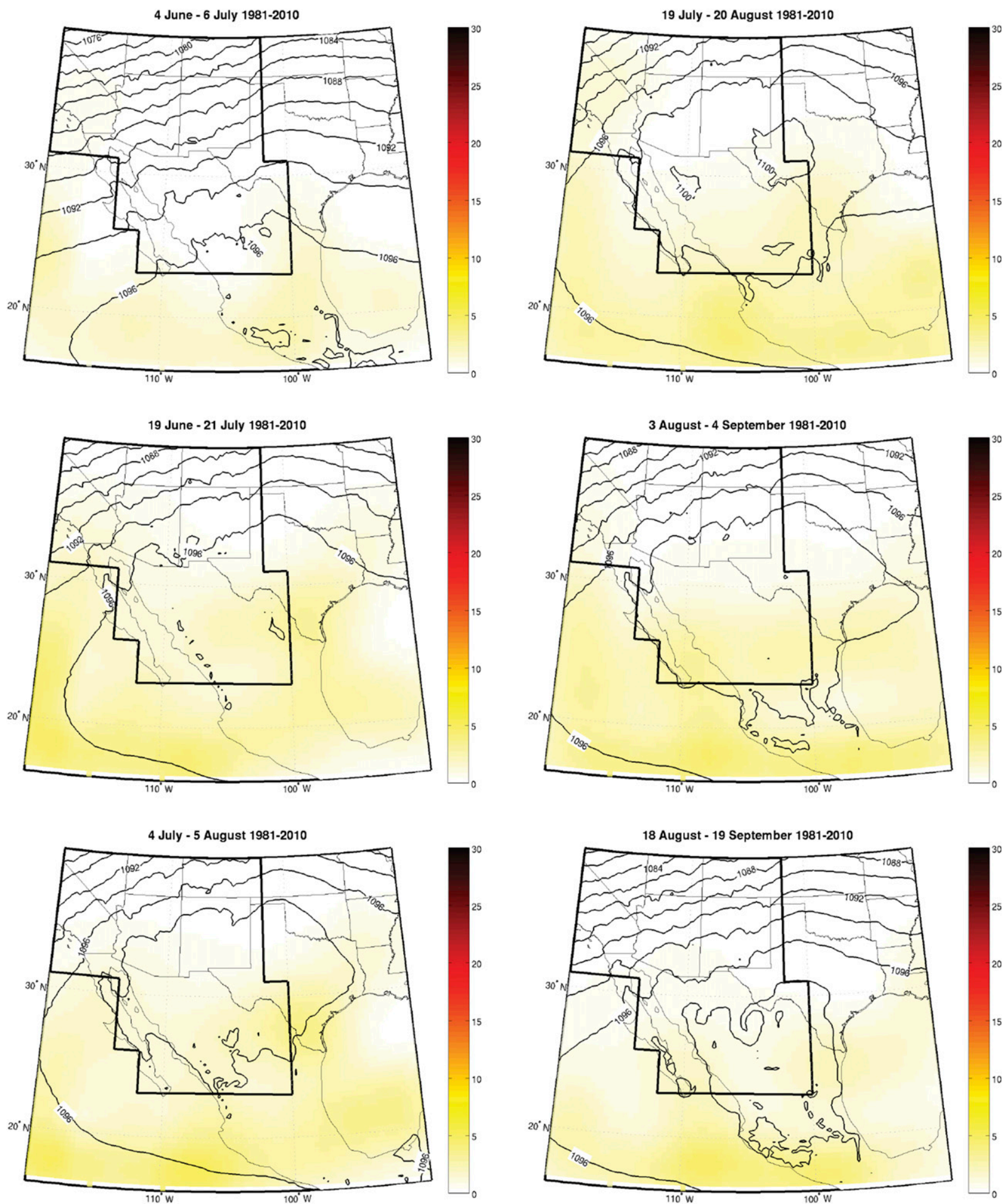

FIG. 7. 1981-2010 raw NCEP-NCAR Reanalysis IV track density. Analysis intervals include (top left) 4 Jun-6 Jul, (middle left) 19 Jun$21 \mathrm{Jul}$, (bottom left) 4 Jul-5 Aug, (top right) 19 Jul-20 Aug, (middle right) 3 Aug-4 Sep, and (bottom right) 18 Aug-19 Sep; 250-hPa geopotential heights are shown with black contours. 


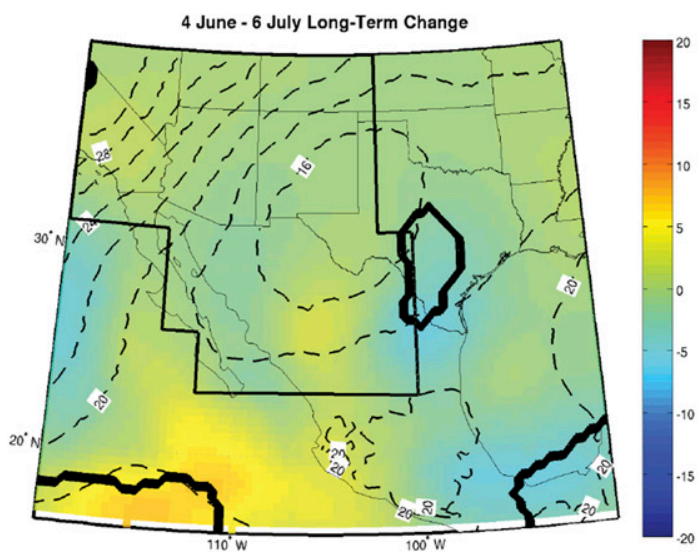

$f=16 \%$

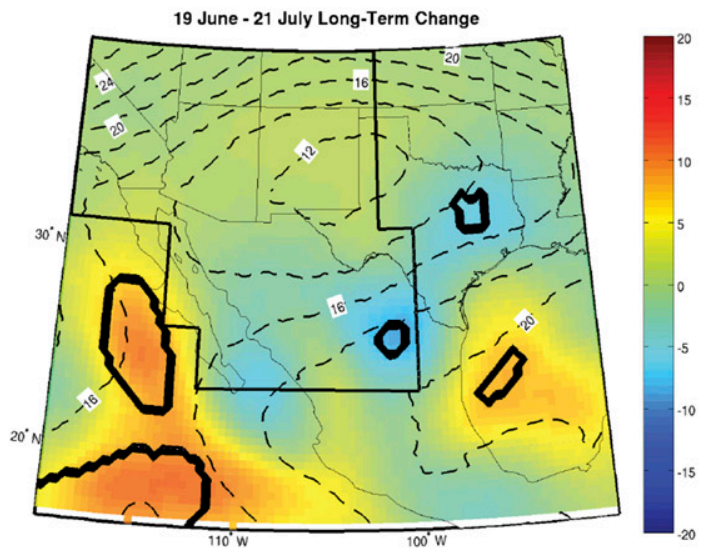

$f=148$

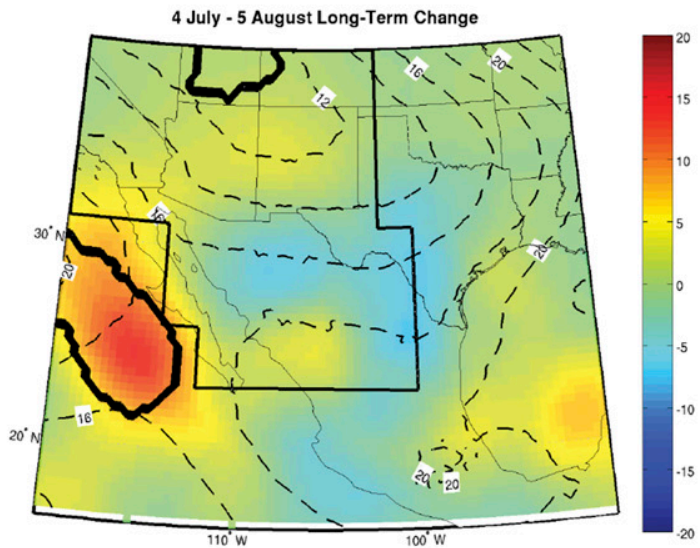

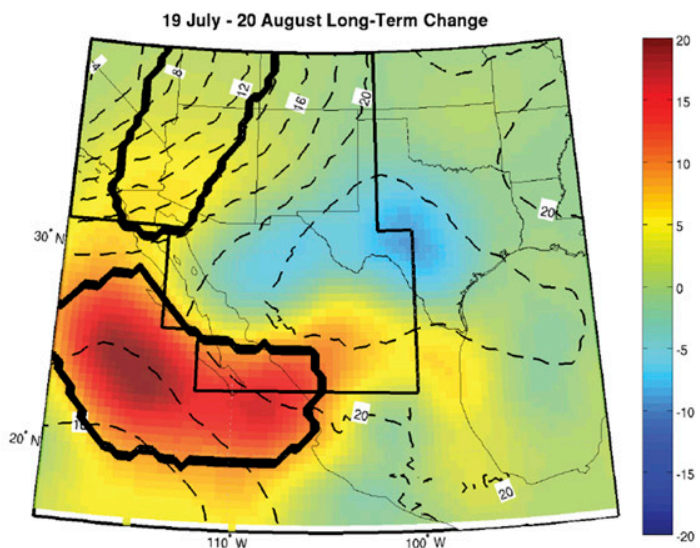

$f=93 \%$

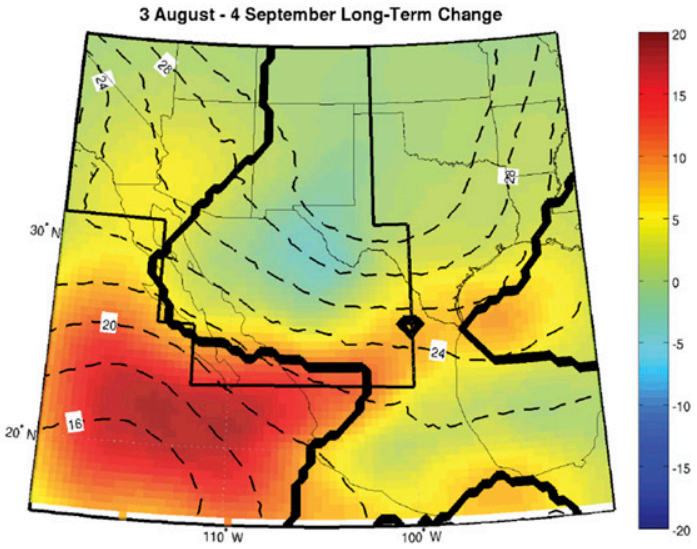

$f=99 \%$

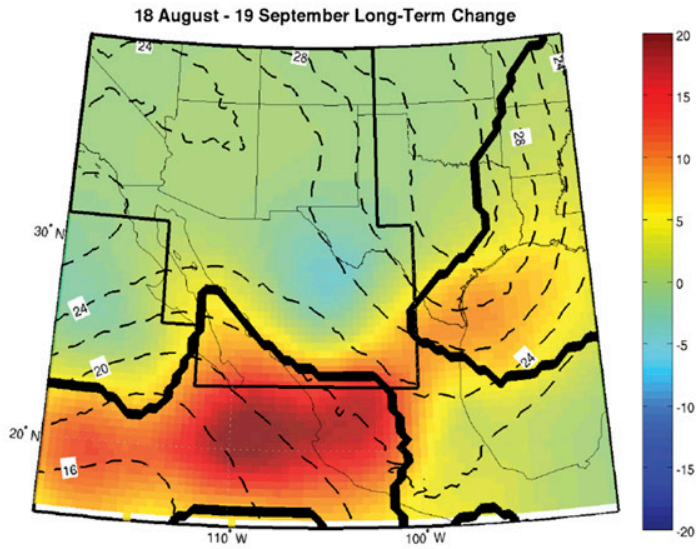

$f=57 \%$

$f=348$

FIG. 8. IV track density change between the 1951-80 and 1981-2010 periods (shaded) and statistical significance of these changes (heavy black contour). Intervals analyzed are (top left) 4 June-6 July, (middle left) 19 June-21 July, (bottom left) 4 July-5 August, (top right) 19 July-20 August, (middle right) 3 August-4 September, and (bottom right) 18 August-19 September. The IVAR region is shown with a lighter contour. Field significance is shown in the bottom left corner of each plot. Positive (negative) 250-hPa geopotential height trends are plotted with dashed (solid) black contours. 
19 September, track density decreased in northwest Mexico, while it increased farther south.

These IV trends are consistent with Table 2, as the number of trough days increased from the early to late analysis periods during 19 July-20 August and 3 August-4 September. This increase in trough days is due to the increased IV track density in the southern domain of the IVAR. While much of the broad area of increased IV track density over the Pacific Ocean is within the region where the addition of satellite data to the forcing reanalysis after 1979 may affect this analysis, there are statistically significant increases in IV track density within the IVAR. The composites during 19 July-20 August and 3 August-4 September are field significant within the IVAR domain. Areas with increased IV track density are along the periphery of the monsoon ridge, while areas with decreased IV track density are near the center of the ridge, where it tended to strengthen most.

To confirm that these trends are not due the addition of satellite data in the NCEP-NCAR reanalysis, IV track density climatology trends between four overlapping time intervals, divided into two 20 -yr segments, are analyzed. The time periods 1951-90, 19612000, 1971-2010, and 1951-2010 (neglecting the years 1971-90) are considered. Track density trends in these periods for 19 July-20 August are plotted in Fig. 9. These results show consistent trends with those of the 60 -yr dataset, and all of them are field significant except for those from the 1951-91 period. Despite there being decreases in IV track density near the NAM ridge center, the 1951-91 period is associated with decreasing $250-\mathrm{hPa}$ heights throughout the western CONUS. Analysis from the other 40 -yr periods shows increases (decreases) in IV track density that nominally coincide with greater (lesser) increases in $250-\mathrm{hPa}$ heights. These $40-\mathrm{yr}$ trends for 3 August to 4 September (see supplemental material) are consistent with results during 19 July to 20 August. Since these changes are mostly consistent across the 40-yr analysis periods, these results suggest the IV climatology trends near the peak of the monsoon season reflect dynamically forced processes, rather than spurious features from the reanalysis forcing. The field significance of the IV climatology trends for all overlapping analysis intervals is shown in Table 5. When 30-yr analysis periods (with 15-yr divisions) are used, these IV track density climatology trends are not resolved, probably due to the effects of natural climate variability. Castro et al. (2009) note the presence of significant monsoon precipitation variability in the southwest on the 6-7-yr scale, and Bieda et al. (2009) show that IV climatology is subject to interannual variability.

\section{d. Relationship with NOAA CPC precipitation}

The 24-h precipitation trends for convective days are considered using the CPC precipitation dataset. Figure 10 shows the differences of 24-h CPC precipitation between trough days and no-trough days. During the early monsoon season, the presence of an IV is associated with increased precipitation over the southwest CONUS. This trend persists, but to a lesser extent, during the second half of the monsoon season. The effects of IVs are less pronounced during the latest analysis interval of the season (18 August-19 September), and this may be due to increased moisture in the region from tropical storms contributing to convection on no-trough days and the breakdown of the monsoon ridge, which reduces IV coverage in the southwest CONUS (Fig. 5). Throughout the NAM season, the CPC data show reduced precipitation through the central Plains and increased precipitation in the northeast on trough days, which is consistent with the shift in precipitation patterns over the CONUS at the onset of the NAM (e.g., Higgins et al. 1997).

Precipitation trends from 1951 to 2010 are shown in Figs. 11 and 12. During the 4 June-6 July and 19 June21 July intervals, precipitation increased during the 60-yr record throughout much of the western CONUS, particularly on trough days (Fig. 11). The increases in precipitation on trough days are most pronounced over New Mexico. These changes reflect the fact that enhanced dynamic forcing (i.e., an IV) is needed to force convection early in the NAM season when moisture is limited. Since IV track density did not significantly change during these intervals, these precipitation increases may reflect more favorable atmospheric thermodynamics associated with a warmer climate, as was suggested in Chang et al. (2015). During the 4 July5 August interval in Arizona, precipitation increased on no-trough days but decreased on trough days. Even though these changes do not appear until later in the season based on the IV climatology, these statistically significant precipitation decreases on trough days cover a broad area, and they are consistent with the effects of the displacement of IVs to the periphery of the monsoon ridge, when it approaches its northernmost climatological extent over the Four Corners region of the CONUS.

During the late monsoon season (Fig. 12), CPC precipitation increased throughout the region on no-trough days. Figure 12 shows most of these increases are confined to high terrain, where the diurnal cycle of precipitation dominates absent dynamic forcing from IVs. During the 19 July-20 August and 3 August-4 September intervals, when significant IV track density changes 

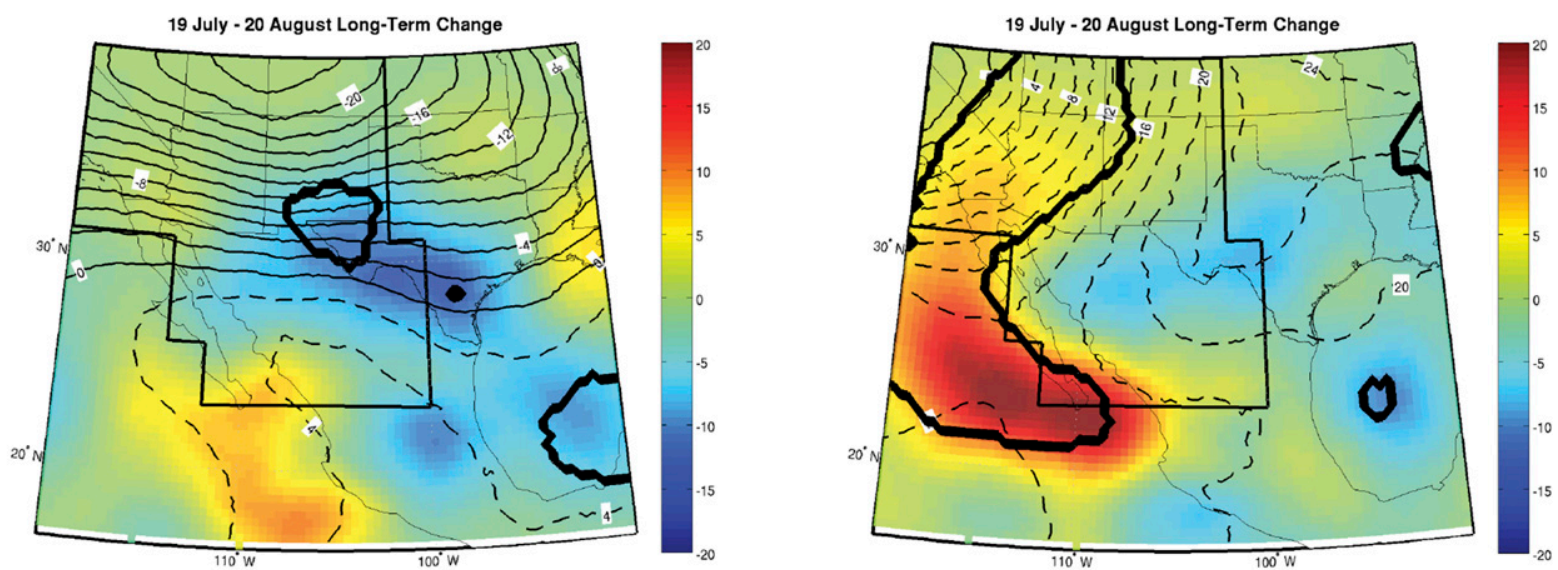

$f=41 \%$

$f=97 \%$
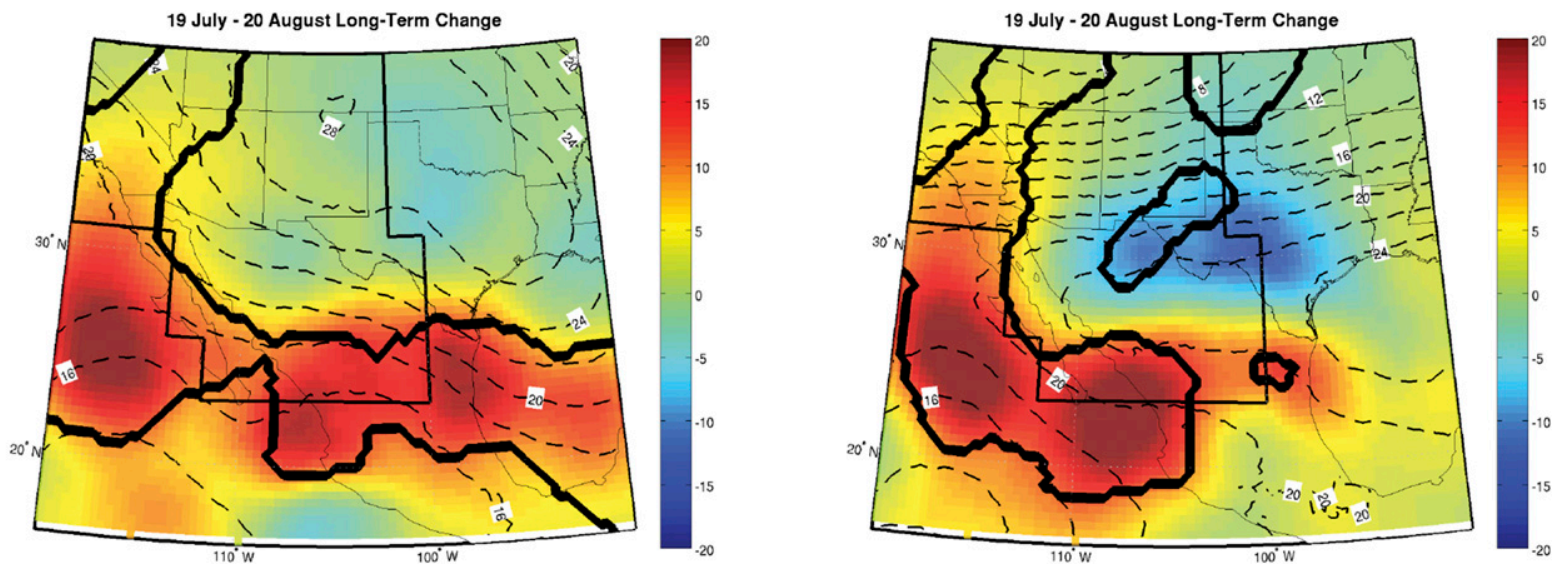

$f=96 \%$

$f=98 \%$

FIG. 9. IV track density change (shaded) and statistical significance of these changes (heavy black contour) during the 19 July-20 August analysis interval. Figure includes comparisons between the (top left) 1951-70 and 1971-90, (top right) 1961-80 and 1981-2000, (bottom left) 1971-90 and 1991-2010, and (bottom right) 1951-70 and 1991-2010 periods. Positive (negative) 250 hPa geopotential height trends are plotted with dashed (solid) black contours.

occurred, precipitation on trough days decreased over Arizona and Nevada. Reduced precipitation in the areas of low terrain on trough days per the CPC results could reflect the changes in organized convection (principally MCSs), which require dynamic forcing to organize (i.e., an IV). This trend likely reflects the reduced influence of IVs within this region, which coincides with their increases in coverage to the south and west. Spatial patterns of IV intensity trends (see supplemental material) from the 1951-2010 period are not consistent with track density trends, so these dynamic changes are likely unrelated to IV intensity.

\section{e. Precipitation trends from high-resolution NWP-type simulations}

Precipitation from the NWP-type convective-permitting simulations of severe weather events on no-trough days during the 19 July-20 August and the 3 August4 September intervals is shown in Fig. 13. This figure shows widespread precipitation increases, particularly in western Arizona. Precipitation increases on no-trough

TABLE 5. Field significance (as a percentage) for IV track density trends during overlapping analysis periods. The 19 Jul-20 Aug and 3 Aug-4 Sep periods are displayed on the middle and right sides, respectively.

\begin{tabular}{lcc}
\hline \hline \multicolumn{1}{c}{ Analysis period } & 19 Jul-20 Aug & 3 Aug-4 Sep \\
\hline $1951-90$ & 41 & 83 \\
$1961-2000$ & 97 & 98 \\
$1971-2010$ & 96 & 97 \\
$1951-70,1991-2010$ & 98 & 98 \\
$1951-80$ & 88 & 97 \\
$1981-2010$ & 35 & 17 \\
\hline
\end{tabular}



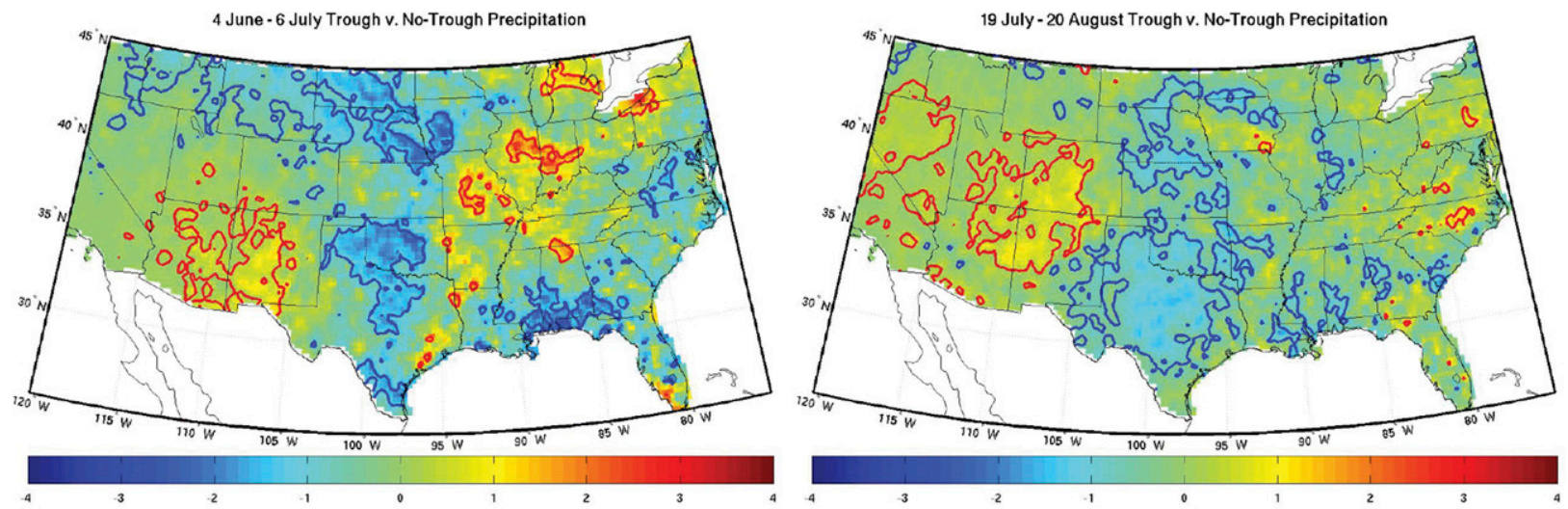

$f>99 \%$

f $>99 \%$
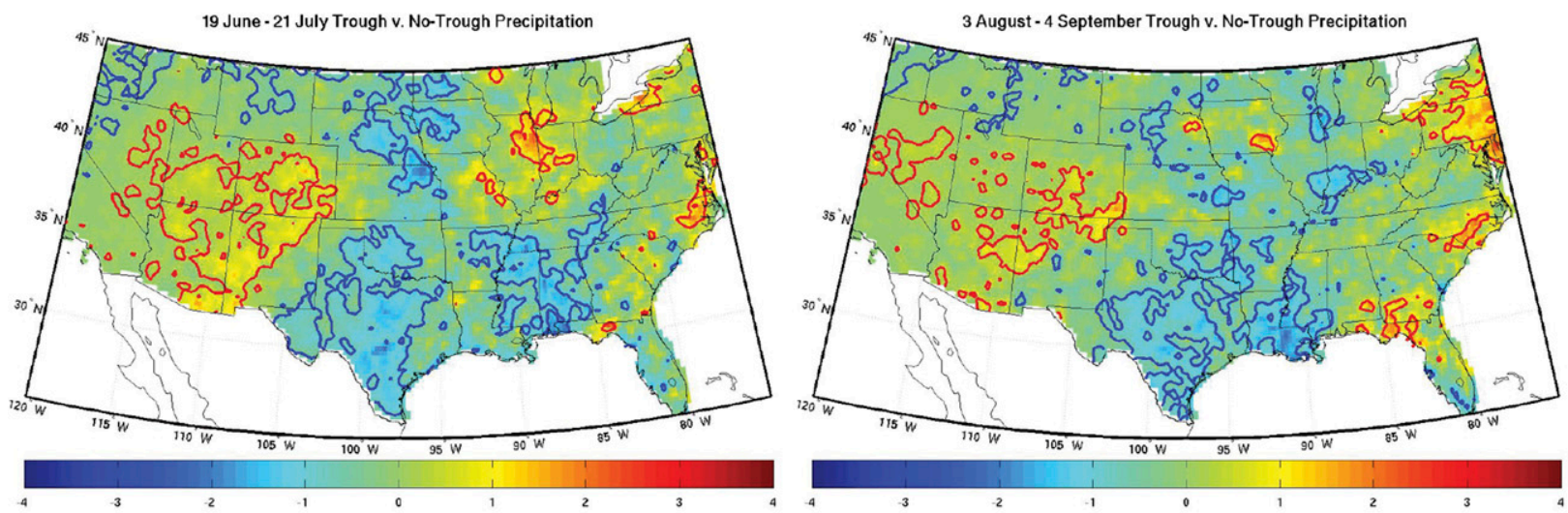

$f>99 \%$

$f>99 \%$
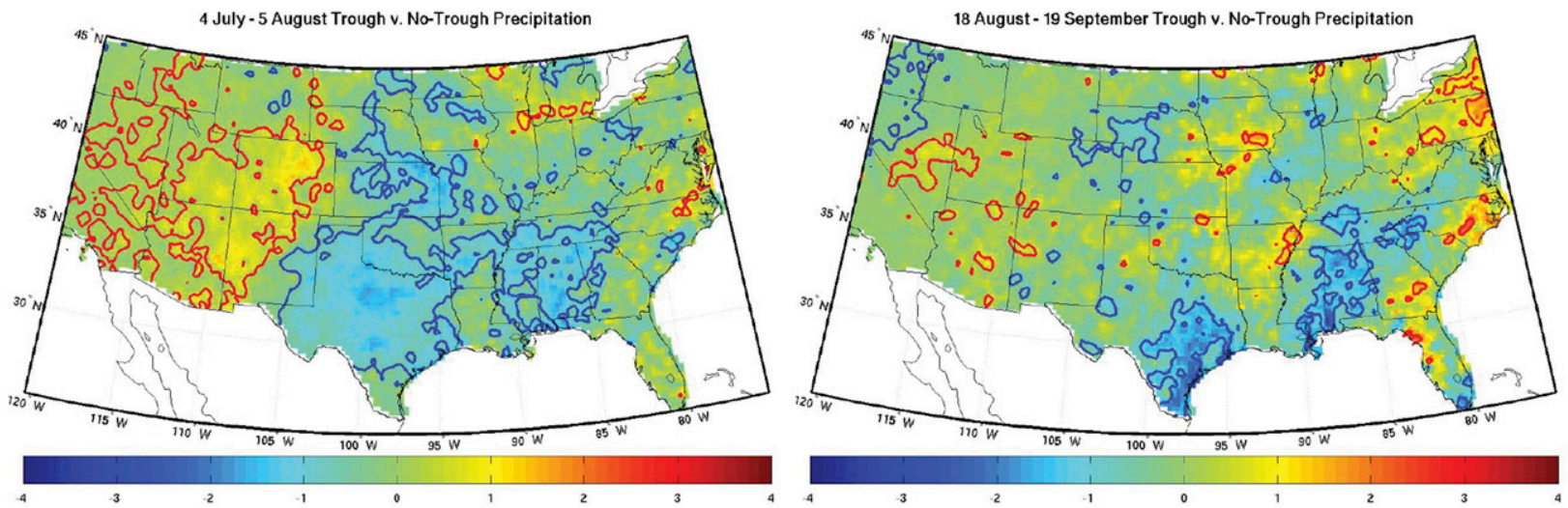

$f>99 \%$

$f-98 \%$

FIG. 10. Difference in 24-h daily average precipitation $(\mathrm{mm})$ between trough days and no-trough days from 1951 to 2010 . Statistically significant positive (negative) areas are contoured in red (blue). Dates include (top left) 4 June-6 July, (middle left) 19 June-21 July, (bottom left) 4 July-5 August, (top right) 19 July-20 August, (middle right) 3 August-4 September, and (bottom right) 18 August19 September. Precipitation data are from the CPC gridded precipitation dataset. Field significance is shown in the bottom left corner of each plot.

days are consistent with the results from the CPC dataset and are field significant. Precipitation increases in western Arizona per the NWP-type simulations are greater than those of the CPC dataset. This may reflect the paucity of precipitation gauges in western Arizona and the subsetting of thermodynamically favorable days, as CPC trends are more similar to NWP simulations when only favorable days are selected (see 

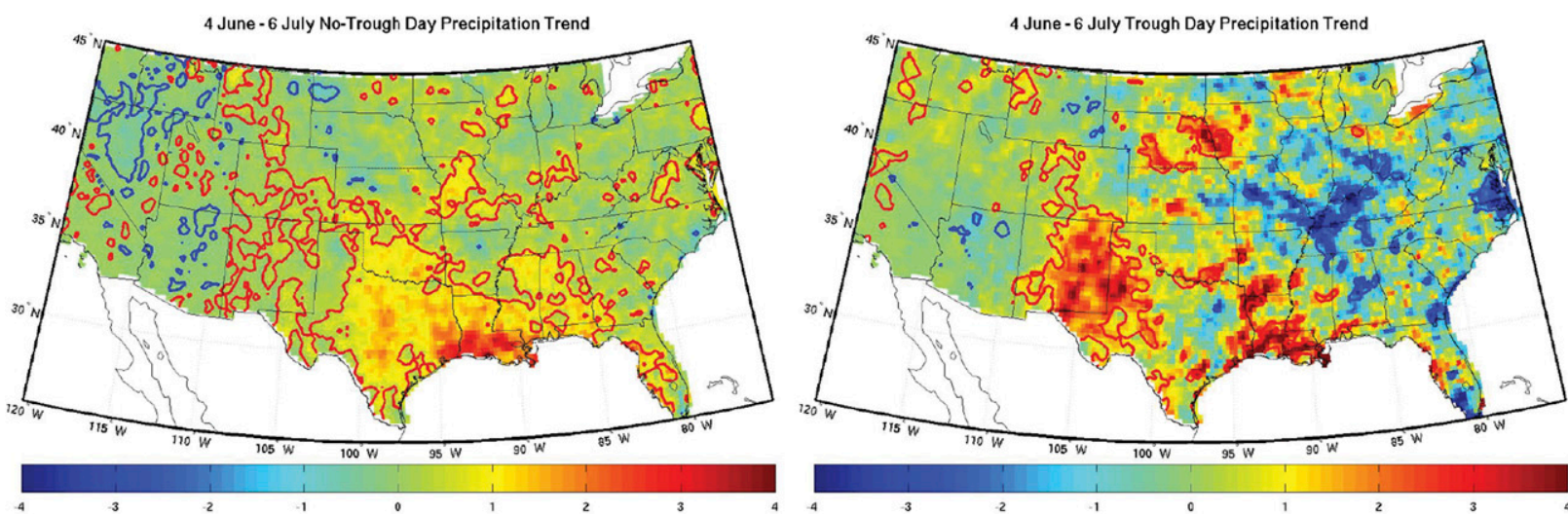

$f>99 \%$

f > 99\%
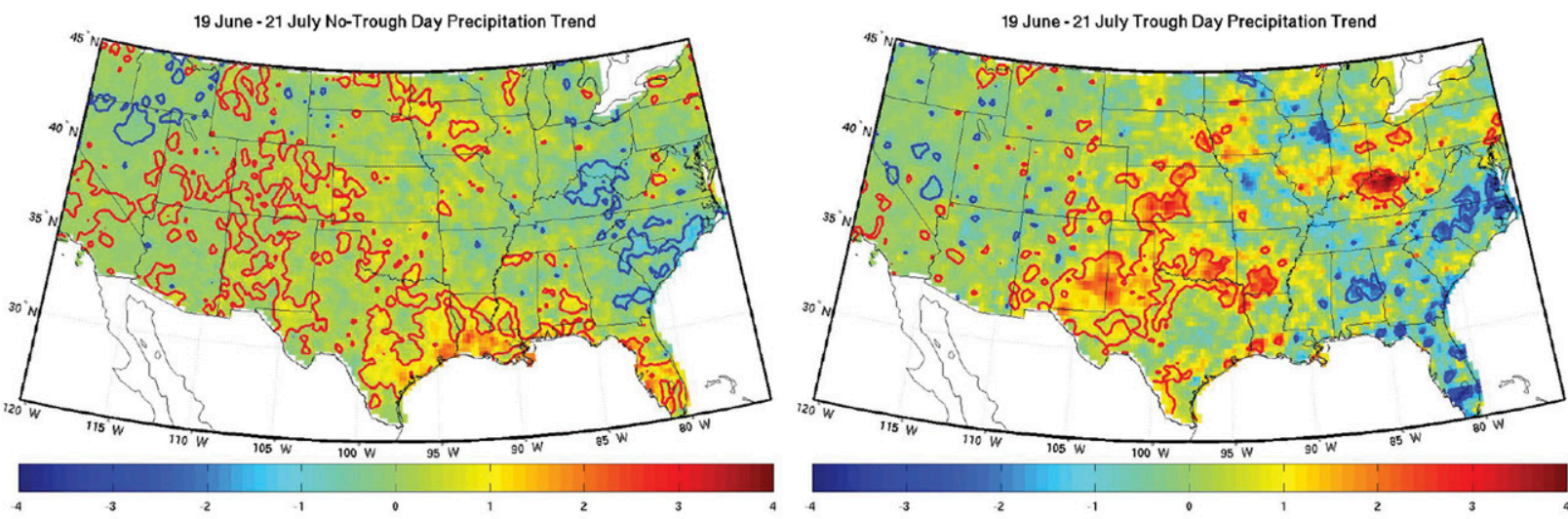

f $>99 \%$

f $-96 \%$
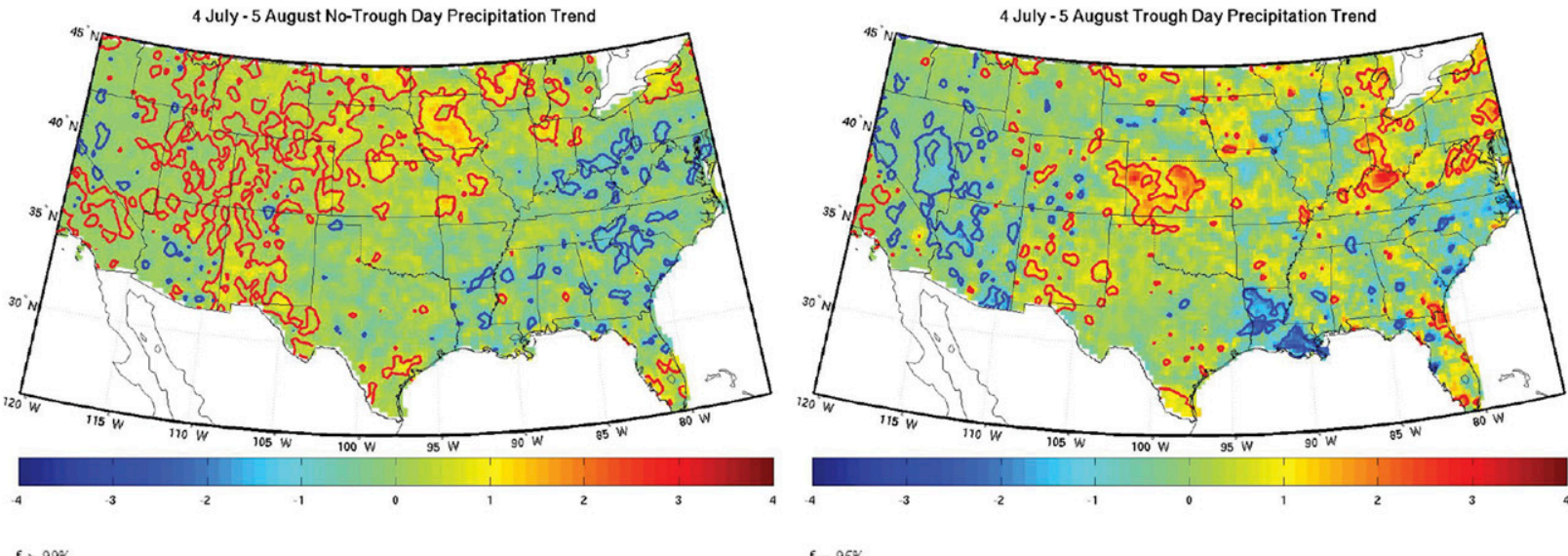

$f>99 \%$

f - 968

FIG. 11. Daily 24-h average precipitation (mm) change between the 1951-80 and 1981-2010 periods for (left) no-trough and (right) trough days. Dates include (top) 4 June-6 July, (middle) 19 June-21 July, and (bottom) 4 July-5 August. Statistically significant positive (negative) areas are contoured in red (blue). Precipitation data are from the CPC gridded precipitation dataset. Field significance is shown in the bottom left corner of each plot.

supplemental material). Modeled precipitation trends for trough days during the same analysis intervals are shown in Fig. 14, which shows precipitation decreases in the low deserts of southeastern and central Arizona on trough days in nearly the same locations as in the CPC dataset. These trends are field significant during the 3 August-4 September interval. The consistency of the trends derived from the high-resolution 

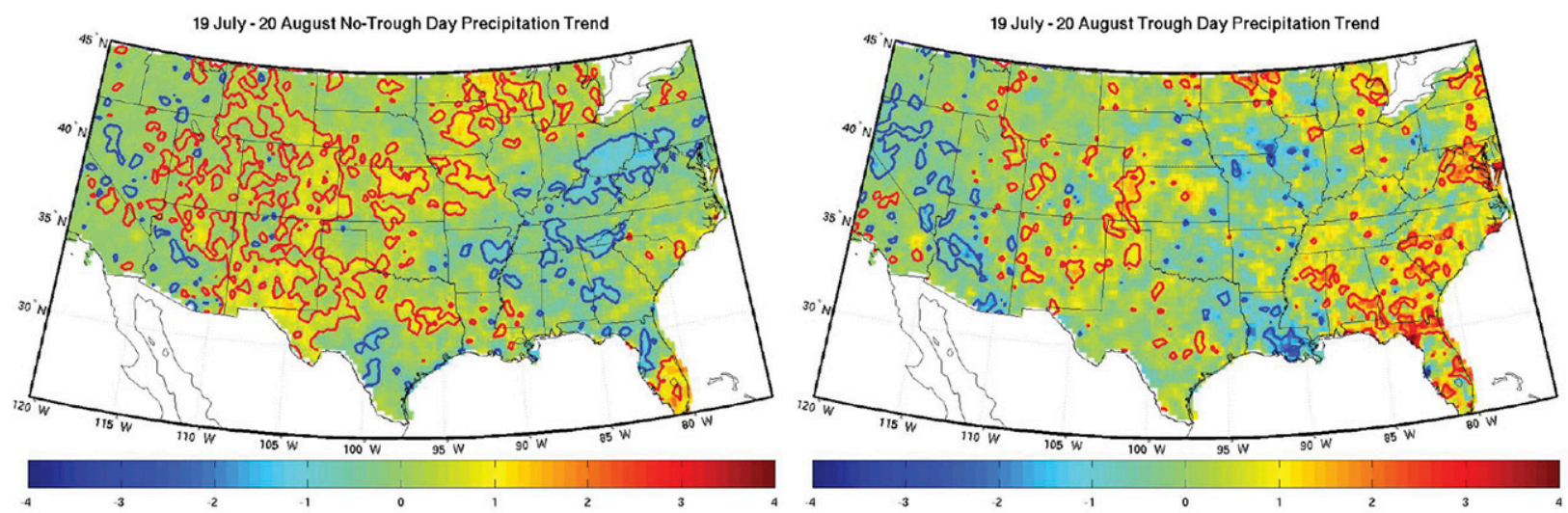

$f>99 \%$

$\mathrm{f}-94 \%$
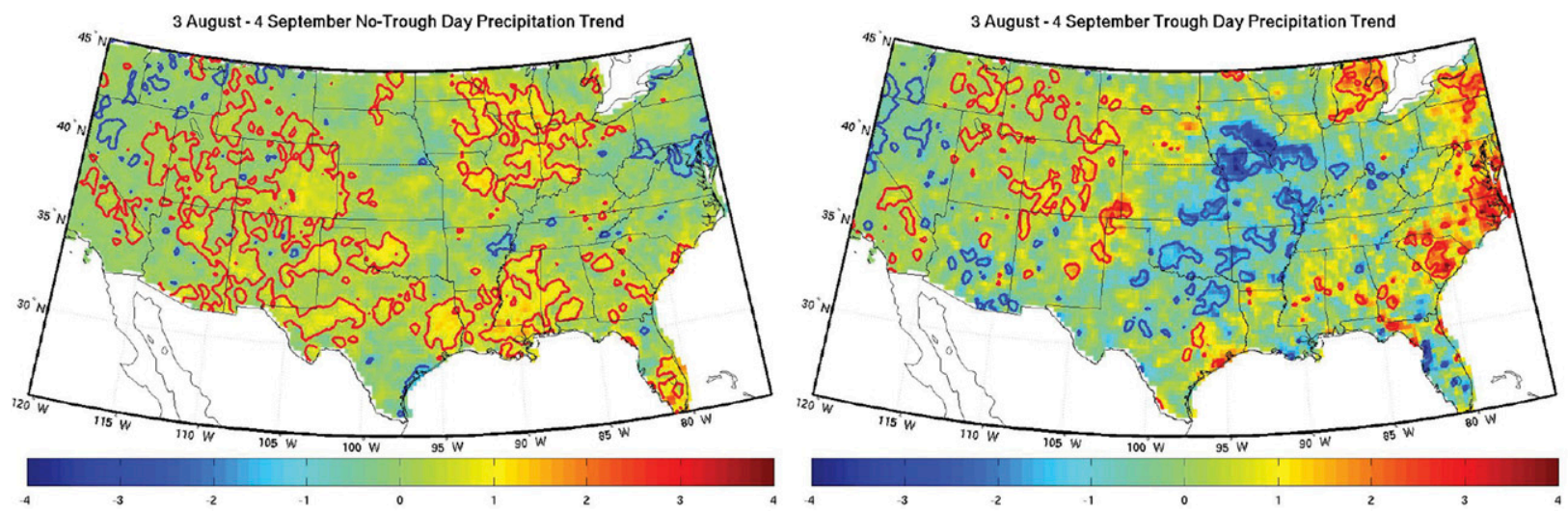

f > $99 \%$

$f-94 \%$
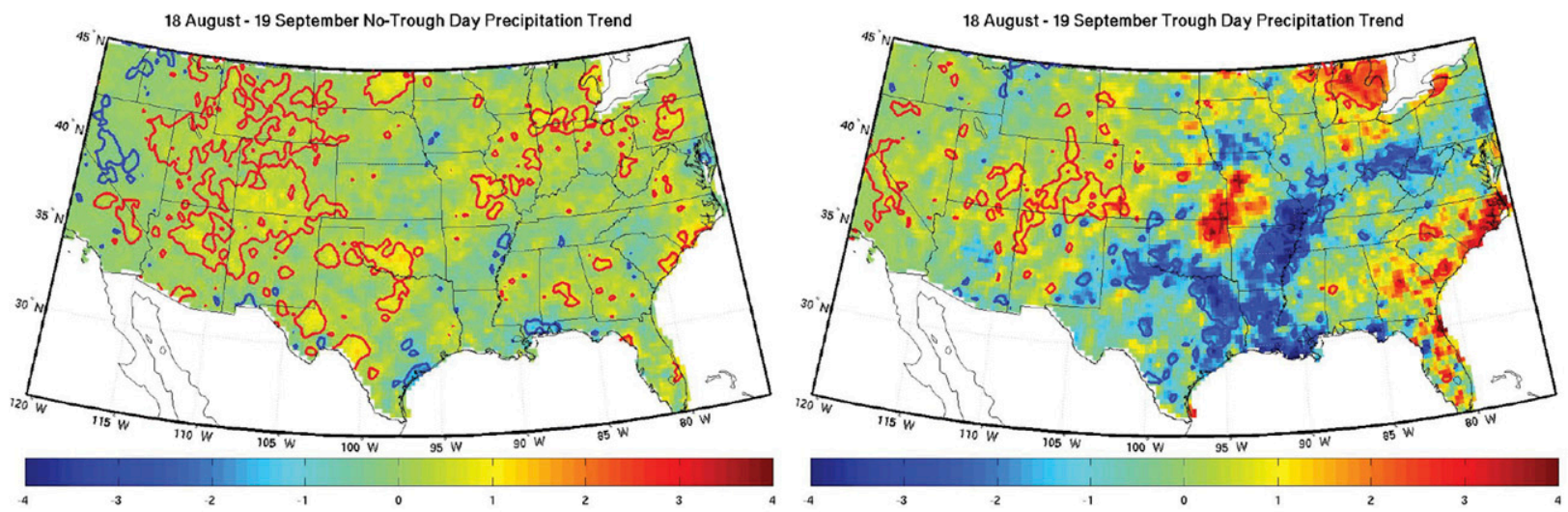

$f>99 \%$

$f-94 \%$

FIG. 12. Daily 24-h average precipitation ( $\mathrm{mm}$ ) change between the $1951-80$ and $1981-2010$ periods for (left) no-trough and (right) trough days. Dates include (top) 19 July-20 August, (middle) 3 August-4 September, and (bottom) 18 August-19 September. Statistically significant positive (negative) areas are contoured in red (blue). Precipitation data are from the CPC gridded precipitation dataset. Field significance is shown in the bottom left corner of each plot.

simulations and the CPC dataset suggests that precipitation trends associated with NAM convection can effectively be modeled, using the dynamically downscaled reanalysis data to drive convectivepermitting simulations.

\section{f. Physical causes of IV track density changes}

To assess the physical causality of observed IV climatology trends, characteristics of upper-tropospheric flow and dynamics during time periods at which an IV is 

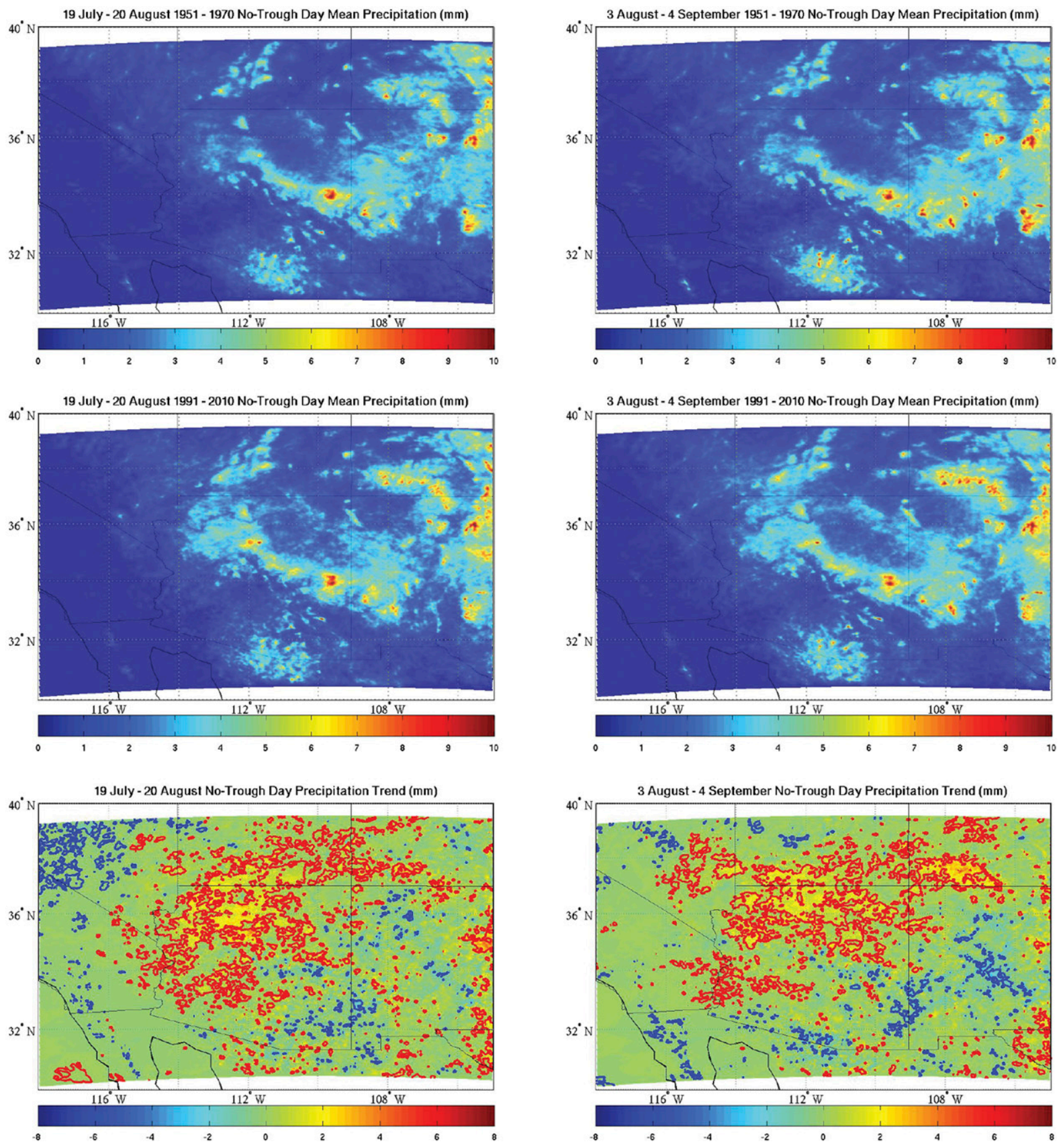

FIG. 13. WRF high-resolution 24-h daily average precipitation $(\mathrm{mm})$ on all no-trough days with favorable thermodynamics during the (top) 1951-70 and (middle) 1991-2010 monsoon seasons for the dates (left) 19 July-20 August and (right) 3 August-4 September. (bottom) The differences between the two time periods are also shown. Statistically significant positive (negative) areas are contoured in red (blue). Field significance is shown in the bottom left corners of the bottom plots.

observed are evaluated. Composite analysis, using a two-tailed Student's $t$ test with $90 \%$ significance and a field significance test, between the early and late analysis periods of geopotential height at 1200 UTC from the regridded RCM is performed for trough days when significant changes are observed (1900 July-20 August and 3 August-4 September) (Fig. 15). Based on this analysis, statistically significant height increases are observed throughout Central America and the Gulf of Mexico. These height increases extend through the west central 

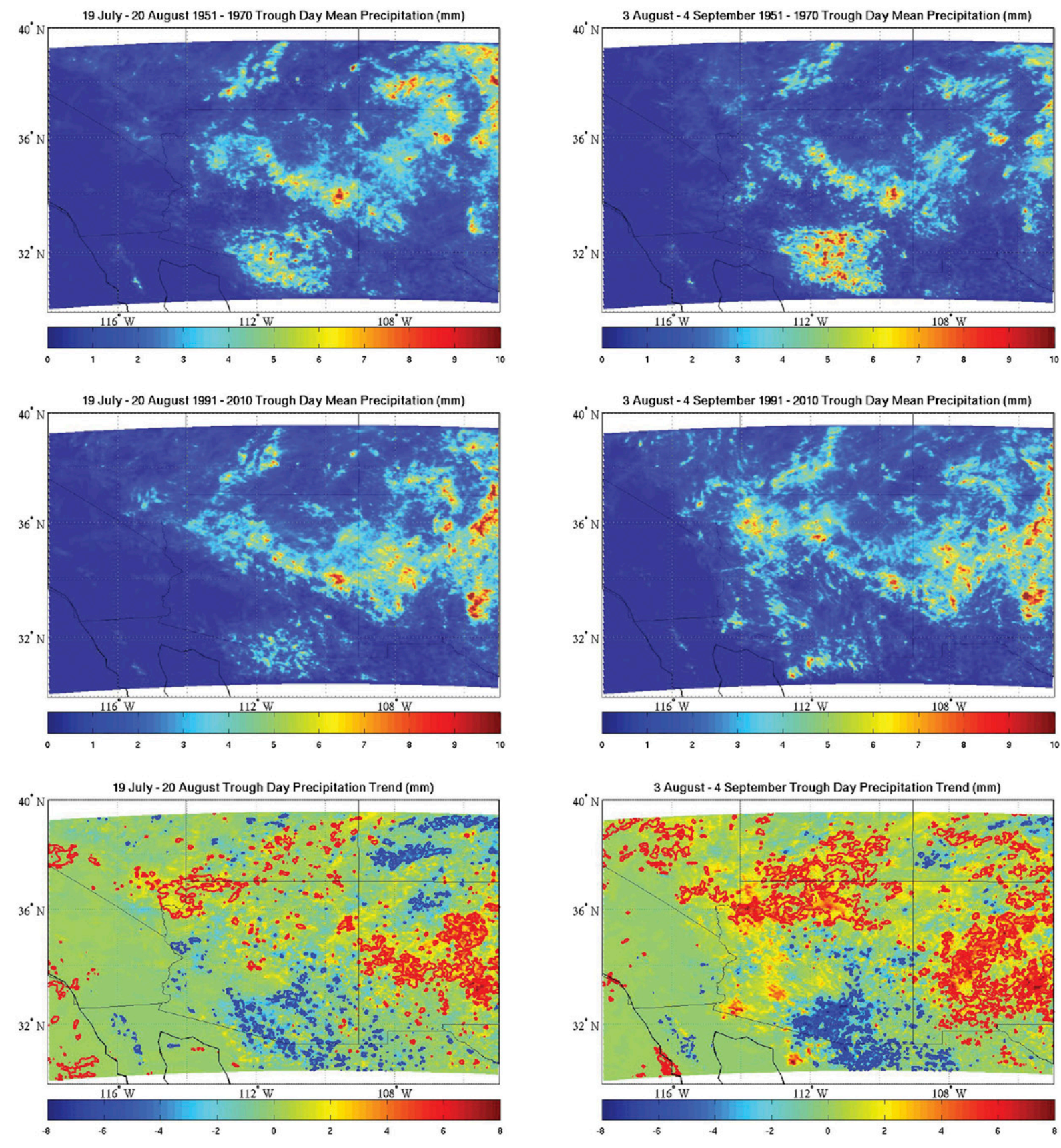

FIG. 14. As in Fig. 13, but for all trough days with favorable thermodynamics.

CONUS into Canada. Comparisons of the monsoon ridge during these periods show this feature is strengthening.

The same composite analysis methods are used on zonal and meridional components of $250-\mathrm{hPa}$ wind. Zonal wind composites (see supplemental material) suggest that easterly winds associated with IV propagation are being displaced south as the monsoon ridge strengthens. Flow became increasingly westerly in the southwest CONUS, and changes are statistically significant during the 19 July-20 August interval. Meridional wind (see supplemental material) became more northerly over the Mississippi Valley and more southerly along the California coast. This strengthening anticyclonic flow may advect newly formed IVs farther south, keeping them out of northern Mexico. Increased southerly flow on the west side of the monsoon ridge 

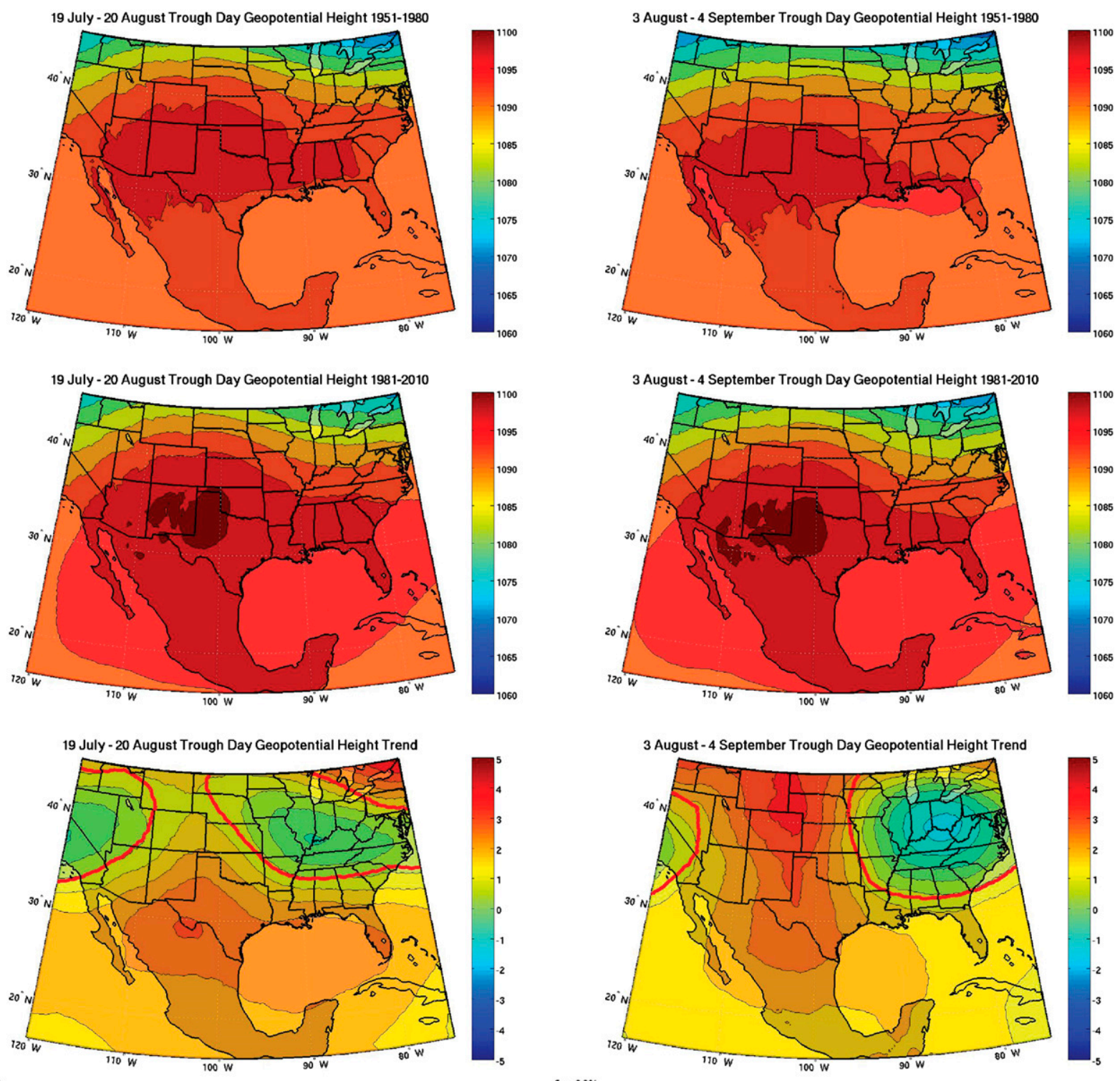

$f>99 \%$

f > $99 \%$

FIG. 15. Composite 250-hPa heights (dm) on all trough days during the (top) 1951-80 and (middle) 1981-2010 monsoon seasons for (left) 19 July-20 August and (right) 3 August-4 September. (bottom) The differences between the two time periods are also shown. Statistically significant positive (negative) areas are contoured in red (blue). Field significance of trends is shown in the bottom left corners of the bottom plots.

may advect features north around the high pressure. This increased southerly flow west of the NAM ridge is consistent with the increased IV track density over California.

IV track density changes are reflected in the $250-\mathrm{hPa}$ PV trends (Fig. 16). PV is a useful proxy for the presence of cyclonic (or anticyclonic) motion, as it is proportional to the vorticity of an air parcel, while being conserved for adiabatic motion (Holton 2004). The PV minimum associated with the monsoon ridge center strengthened during the 1951-2010 period, as the flow patterns across northwest Mexico became more anticyclonic. These PV patterns are physically consistent with a strengthening monsoon ridge.

\section{g. Observed vertical wind shear trends}

To verify the trends in IV track density climatology, the changes of the magnitude of the wind shear vector are examined in radiosonde records throughout the southwest CONUS during the years 1951-2010, when data are available. Wind shear at three levels, including surface to $450 \mathrm{hPa}, 700-400 \mathrm{hPa}$, and $700-300 \mathrm{hPa}$, 

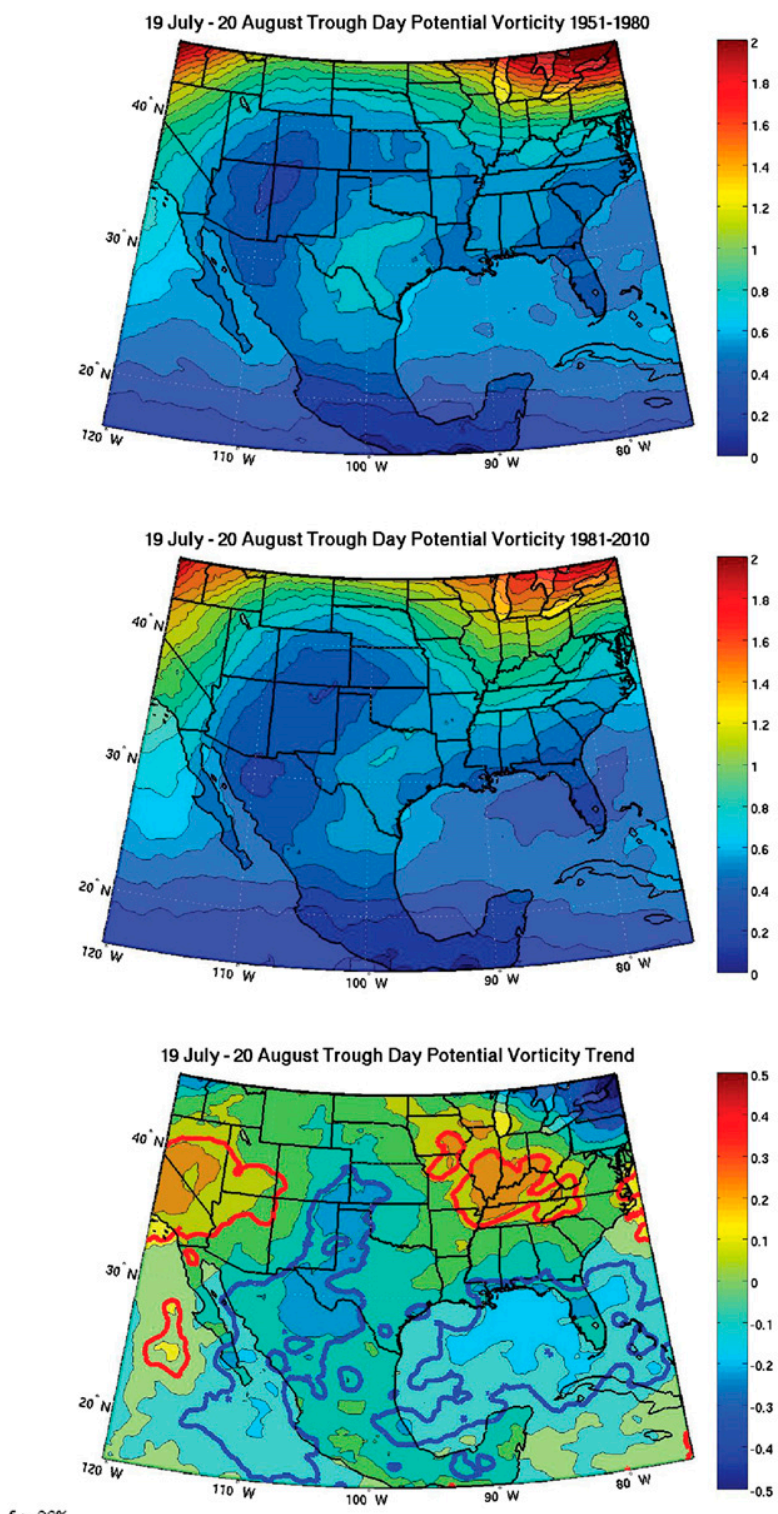
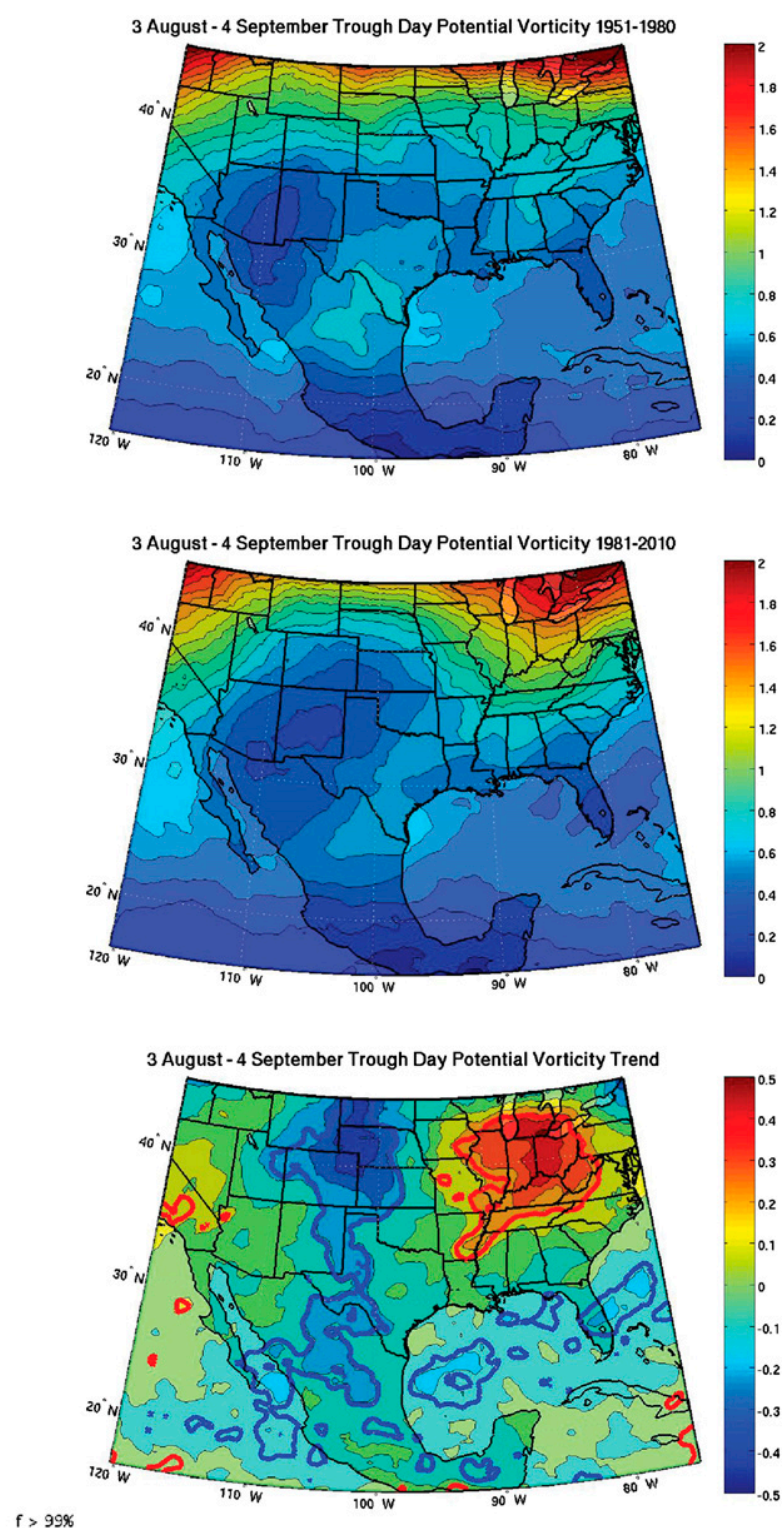

$\mathrm{f}>99 \%$

FIG. 16. Composite 250-hPa potential vorticity (PVU) on all trough days during the (top) 1951-80 and (middle) 1981-2010 monsoon seasons for (left) 19 July-20 August and (right) 3 August-4 September. (bottom) The differences between the two time periods are also shown. Statistically significant positive (negative) areas are contoured in red (blue). Field significance of trends is shown in the bottom left corners of the bottom plots.

is analyzed. For the surface to $450-\mathrm{hPa}$ level, which is similar to 0-6-km shear, only morning soundings (1200 UTC soundings or an average of the 0900 and 1500 UTC soundings) are considered. For the other levels, the morning and evening soundings are used (1200 or 1500 UTC and 0000 or 0300 UTC, respectively). Soundings from other times are not analyzed. The correlation coefficients and $t$ statistics for the trends of wind shear from radiosonde observations on trough days and all convective days during the 19 July20 August and 3 August-4 September intervals are shown in Table 6 . When computing $t$ statistics, each observation is assumed independent. Stations include Albuquerque, New Mexico; Desert Rock, Nevada; El Paso, Texas; Flagstaff, Arizona; San Diego, California; and Tucson, Arizona. Wind shear increased significantly at many of these stations and at each level, particularly in Desert Rock and San Diego, where IV track density increased. El Paso is located near the area of reduced IV track density close to the NAM ridge center, and shear significantly decreased there on all convective days and on trough days, particularly when 
TABLE 6. Correlation coefficients and $t$ statistics for (from left to right) surface to 450-hPa (morning soundings only), 700-400-hPa, and 700-300-hPa wind shear trends. Years used include 1951-2014, whenever data are available. Wind shear trends on all convective days are shown in the top rows, and trends from trough days are shown in the bottom rows. Bold values are statistically significant.

\begin{tabular}{|c|c|c|c|c|c|c|}
\hline \multirow[b]{2}{*}{ Correlation coefficient (all days) } & 19 Jul-19 Aug & \multirow{2}{*}{$\frac{3 \text { Aug-3 Sep }}{\text { Surface- }-450 \mathrm{hPa}}$} & \multirow{2}{*}{$\frac{19 \mathrm{Jul}-19 \mathrm{Aug}}{700-400 \mathrm{hPa}}$} & \multirow{2}{*}{$\frac{3 \text { Aug-3 Sep }}{700-400 \mathrm{hPa}}$} & \multirow{2}{*}{$\frac{19 \mathrm{Jul}-19 \mathrm{Aug}}{700-300 \mathrm{hPa}}$} & \multirow{2}{*}{$\frac{3 \text { Aug-3 Sep }}{700-300 \mathrm{hPa}}$} \\
\hline & Surface $-450 \mathrm{hPa}$ & & & & & \\
\hline Albuquerque, NM & 0.032 & 0.024 & 0.008 & 0.001 & 0.035 & -0.001 \\
\hline Desert Rock, NV & 0.205 & 0.077 & 0.102 & 0.021 & 0.094 & 0.011 \\
\hline El Paso, TX & $-\mathbf{0 . 0 5 0}$ & -0.057 & $-\mathbf{0 . 0 5 8}$ & -0.045 & -0.051 & -0.054 \\
\hline Flagstaff, AZ & 0.086 & 0.058 & 0.046 & 0.023 & 0.056 & 0.012 \\
\hline San Diego, CA & 0.003 & 0.019 & 0.070 & 0.032 & 0.100 & 0.041 \\
\hline Tucson, AZ & -0.004 & -0.017 & 0.012 & 0.024 & 0.035 & 0.024 \\
\hline \multicolumn{7}{|l|}{$t$ statistic } \\
\hline Albuquerque, NM & 1.407 & 1.055 & 0.469 & 0.072 & 2.067 & -0.031 \\
\hline Desert Rock, NV & 8.120 & 3.058 & 6.046 & 1.239 & 5.615 & 0.661 \\
\hline El Paso, TX & -2.147 & -2.494 & -3.374 & -2.643 & -2.982 & -3.154 \\
\hline Flagstaff, AZ & 3.395 & 2.294 & 2.527 & 1.288 & 3.113 & 0.656 \\
\hline San Diego, CA & 0.120 & 0.729 & 4.181 & 1.932 & 6.030 & 2.449 \\
\hline \multirow[t]{2}{*}{ Tucson, AZ } & 0.161 & -0.714 & 0.732 & 1.423 & 2.107 & 1.404 \\
\hline & 19 Jul-19 Aug & 3 Aug-3 Sep & 19 Jul-19 Aug & 3 Aug-3 Sep & $19 \mathrm{Jul}-19 \mathrm{Aug}$ & 3 Aug-3 Sep \\
\hline Correlation coefficient (trough days) & Surface $-450 \mathrm{hPa}$ & a Surface $-450 \mathrm{hPa}$ & $700-400 \mathrm{hPa}$ & $700-400 \mathrm{hPa}$ & $700-300 \mathrm{hPa}$ & $\overline{700-300 \mathrm{hPa}}$ \\
\hline Albuquerque, NM & 0.016 & -0.035 & 0.030 & -0.144 & 0.012 & -0.126 \\
\hline Desert Rock, NV & 0.396 & 0.360 & 0.265 & 0.153 & 0.234 & 0.091 \\
\hline El Paso, TX & -0.081 & 0.001 & -0.061 & -0.100 & -0.080 & -0.147 \\
\hline Flagstaff, AZ & 0.123 & 0.070 & 0.033 & 0.023 & 0.115 & 0.003 \\
\hline San Diego, CA & 0.226 & 0.154 & 0.166 & 0.135 & 0.196 & 0.172 \\
\hline Tucson, AZ & 0.003 & 0.052 & 0.016 & -0.046 & 0.037 & 0.024 \\
\hline \multicolumn{7}{|l|}{$t$ statistic } \\
\hline Albuquerque, NM & 0.289 & -0.508 & 0.701 & -2.839 & 0.270 & -2.459 \\
\hline Desert Rock, NV & 6.646 & 4.973 & 6.745 & 3.103 & 5.909 & 1.831 \\
\hline El Paso, TX & -1.413 & 0.013 & -1.407 & -1.919 & -1.871 & -2.870 \\
\hline Flagstaff, AZ & 1.893 & 0.916 & 0.708 & 0.414 & 2.528 & 0.060 \\
\hline San Diego, CA & 3.479 & 1.906 & 4.001 & 2.661 & 4.764 & 3.449 \\
\hline Tucson, AZ & 0.051 & 0.743 & 0.375 & -0.902 & 0.870 & 0.473 \\
\hline
\end{tabular}

middle troposphere shear is considered. Figure 17 shows the trends at Desert Rock and El Paso. The 50-60-yr radiosonde-based vertical shear trends within the NAM region corroborate the reanalysis trends showing reduced IV coverage in northwest Mexico. The fact that these wind shear trends are observed when all convective days are considered is consistent with observed strengthening of the NAM ridge, where the upper-troposphere circulation regime has become increasingly anticyclonic throughout the NAM region.

\section{Discussion}

Within a dynamically downscaled reanalysis, the NAM ridge has expanded and intensified during the second half of the period from 1950 to 2010. IVs have likely been displaced farther from the ridge center, resulting in decreased IV coverage in the southwest CONUS during the peak of the monsoon (late July to mid-August) (Fig. 18). Changes in IV coverage are associated with statistically significant precipitation decreases during identified trough days in the Southwest, particularly in Arizona. Conversely, analysis of thermodynamic trends suggests that precipitation on no-trough days increased due to enhanced moisture and atmospheric instability. Differing behaviors in the character of precipitation on trough versus no-trough days exist in observed CPC precipitation records and convectivepermitting NWP-type simulations. As previous work has established a relationship between IVs and the coverage of organized convection (e.g., Bieda et al. 2009; Pytlak et al. 2005), we infer, given observed trends, that reduced IV activity will likely decrease the frequency of monsoon organized convection in the Southwest, if these trends persist in the future.

Given these precipitation trends, we propose that the atmosphere has become more thermodynamically favorable, but less dynamically favorable, for organized convection in the southwest CONUS during the NAM. In an average sense, the recent atmospheric regime after 

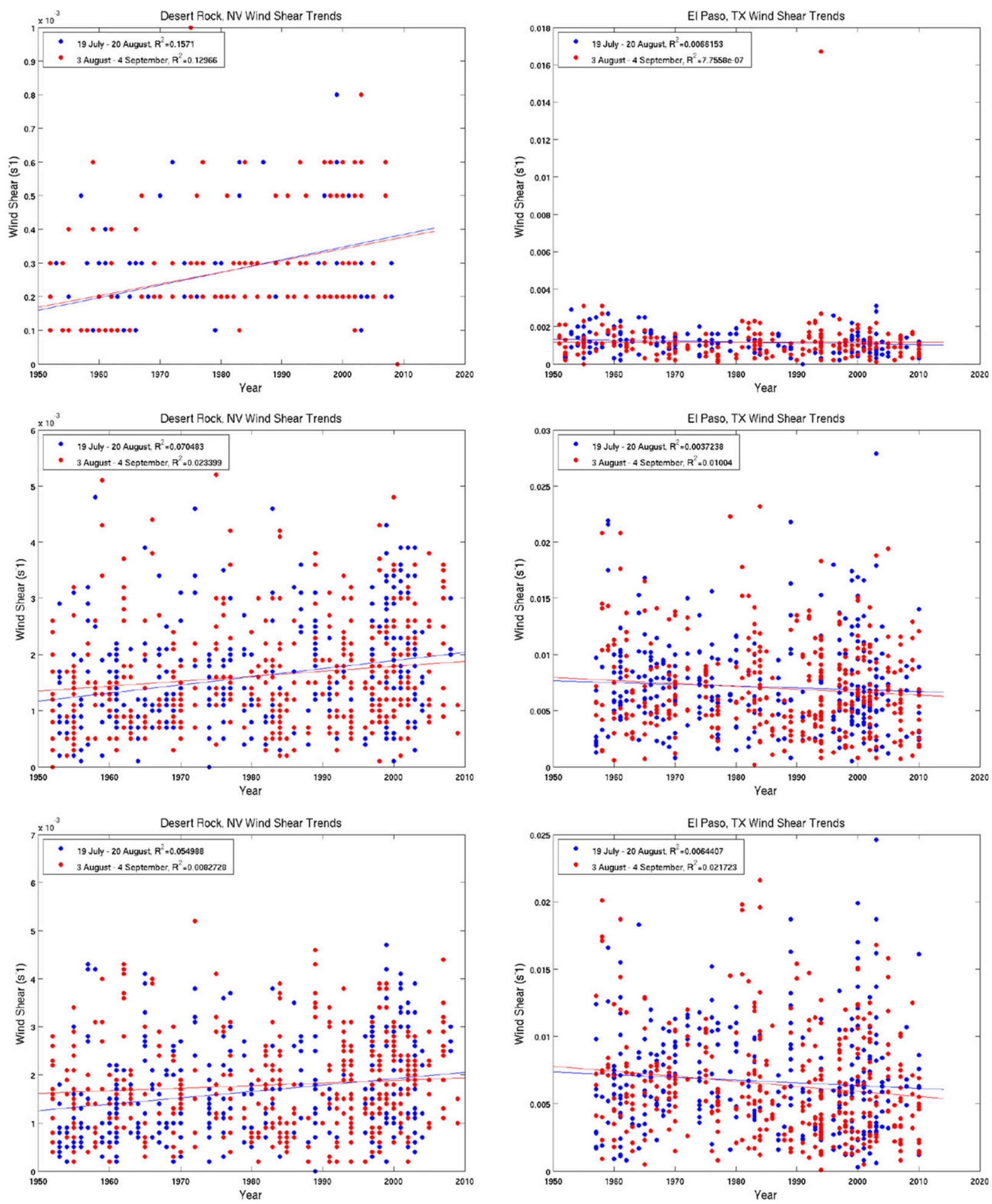

FIG. 17. Vertical wind shear observations at (left) Desert Rock, Nevada, and (right) El Paso, Texas. Shear values from all trough days during the 19 Jul-20 Aug and 3 Aug-4 Sep analysis periods are shown with trend lines and $R^{2}$ values from linear regression. (top) Surface to $450-\mathrm{hPa}$ shear based on only morning soundings, (middle) 700-400-hPa shear based on all soundings, and (bottom) 700-300-hPa shear based on all soundings (bottom) are shown. 


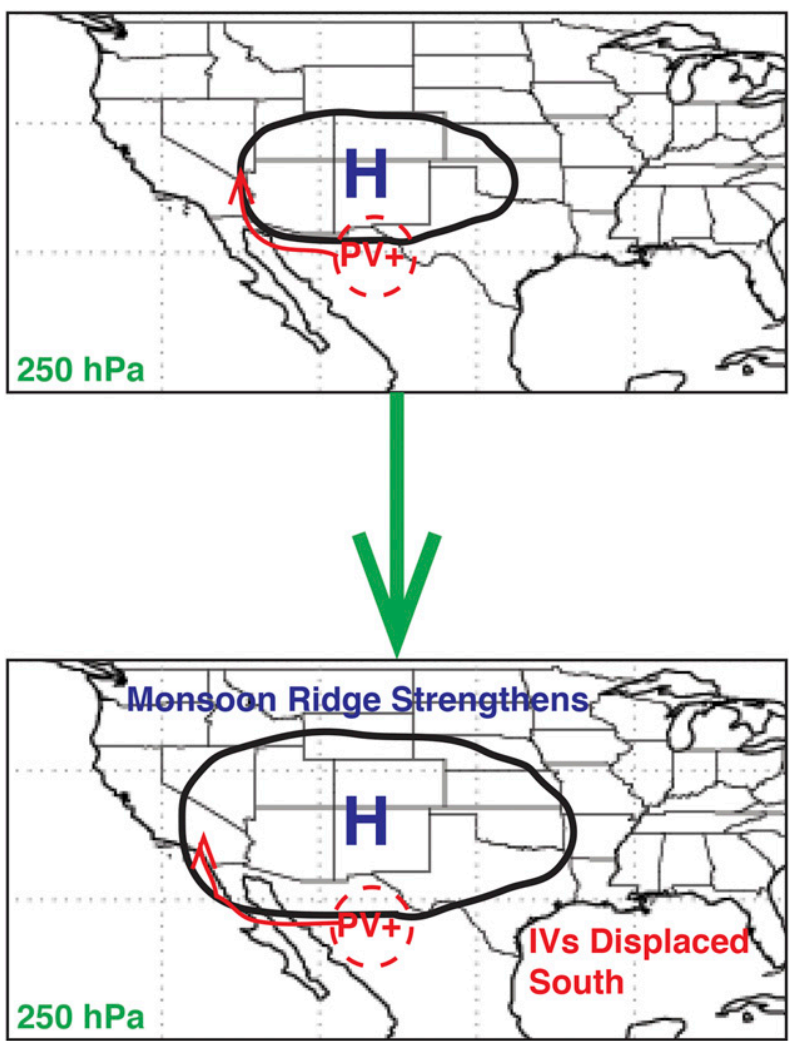

FIG. 18. Conceptual illustration of changing upper troposphere $(250 \mathrm{hPa})$ dynamics during the NAM season. The strengthening monsoon high is displacing PV anomalies (IVs) away from its center.

1980 has become favorable for monsoon thunderstorms that tend to be more phase-locked to the terrain, with less propensity to organize and propagate. The changes in IVs from our RCM simulations are consistent with changes to wind shear in the observed radiosonde records throughout the region. We emphasize that CPC precipitation for trough versus no-trough days and the analyzed wind shear trends from the radiosonde data are two sources of observational data, independent of the RCM simulation, that corroborate these conclusions.

To be clear, our present work is not a formal climate change attribution-type study of IV changes during the NAM. Our observational analysis cannot definitively address this question, given natural climate variability. Bieda et al. (2009) investigated the effects of natural climate variability on IV track density. They showed that IV track density increases in coverage during the negative phase of a combined Pacific variability mode, as originally defined in Castro et al. (2007b), which represents the combination of El Niño-Southern Oscillation and Pacific decadal variability (ENSO-PDV).

Despite the fact that we cannot explicitly attribute the observed changes in IVs to anthropogenic climate change, we have shown that intensification of the NAM ridge described previously fits into a larger, wellestablished conceptual picture, with retreat of the westerly jet to higher latitudes (e.g., Archer and Caldeira 2008) and expansion of the tropical Hadley cell and subtropical highs (e.g., Lu et al. 2007; Seidel et al. 2008). IV track density trends from our analysis period (1951-2010) are physically consistent with a strengthening monsoon ridge, where IV tracks are farther away from the ridge axis. The addition of satellite data to the reanalysis forcing in 1979 is likely a lesser factor, because calculating the trends over overlapping time intervals yielded similar results. The intensification of the NAM ridge is consistent with Hsu et al. (2012), who showed global increases in areas affected by monsoons, and Chang et al. (2015), who showed increases in NAM precipitation during the late summer.

Regardless of the exact physical cause of the IV track density trends shown within this study, these trends could have a profound impact on the local climate and vulnerability to severe weather within the Southwest if they persist in the future. If monsoon thunderstorms tend to become more phase-locked to terrain in a more thermodynamically favorable environment, with a reduced tendency to organize and propagate due to a decreased presence of IVs, monsoon precipitation will intensify over the higher terrain, with possibly greater propensity for flooding, while monsoon precipitation will become less frequent in the low deserts. The increase in monsoon precipitation confined to mountainous areas in western North America is consistent with the recent analysis of warm season CPC daily precipitation trends of Chang et al. (2015).

In forthcoming work, we will attempt to establish a physical and statistical connection of IV track changes to anthropogenic climate change by repeating our methodological approach for IV tracking for an ensemble of IPCC global climate change projection models, or RCMs that dynamically downscale these products. Dynamical downscaling of global reanalysis, as performed here, adds value in the sense that 1) IVs are better represented in the regional model simulation, compared to the driving global model and 2) NWP-type simulations with a convective-permitting scale are able to explicitly resolve organized convection to reasonably represent observed precipitation trends on trough and no-trough convective days.

\section{Summary and conclusions}

A climatology of transient IVs within the NAME Tier II region has been constructed from a regional model spanning the years 1951-2010. These data have allowed 
the IV track density climatology to be computed, and analysis of IV track density over time shows regions of statistically significant changes to the number of passing IVs throughout the NAM season. IV track density climatology is significantly increasing in southern Mexico and Southern California, while decreasing slightly over northern Mexico. Analysis of upper-troposphere variables suggests that changes in the strength of the monsoon ridge are diverting IVs away from the ridge center at the peak of the NAM season. These results suggest that IVs are becoming less relevant to the monsoon convective environment in the southwest CONUS due to 1) their movement to the periphery of the monsoon ridge and 2) enhancement of the thermodynamic environment.

This analysis must be replicated with an ensemble of dynamically downscaled GCMs to attribute these trends to anthropogenic climate change. Dynamical downscaling of RCMs to the convection-permitting scale may provide insight into future changes of warm season precipitation in the southwest CONUS, as our analysis of thermodynamically favorable days shows that this modeling methodology can capture precipitation trends that are consistent with the CPC dataset. Thus, the methodological approach outlined in this paper lays out an analysis framework that can be used to assess the impacts of climate change on local dynamics and be extended for impacts assessment.

Acknowledgments. We acknowledge Kevin Hodges for his assistance in troubleshooting the feature tracking code and helping the authors develop the methodology to analyze track density. We also acknowledge Stephen Bieda for providing us with manually plotted IV tracks after 2002. This work was supported by the Strategic Environmental Research and Development Program Project Number RC-2205.

\section{REFERENCES}

Adams, D. K., and A. C. Comrie, 1997: The North American monsoon. Bull. Amer. Meteor. Soc., 78, 2197-2213, doi:10.1175/ 1520-0477(1997)078<2197:TNAM > 2.0.CO;2.

— , and E. P. Souza, 2009: CAPE and convective events in the Southwest during the North American monsoon. Mon. Wea. Rev., 137, 83-98, doi:10.1175/2008MWR2502.1.

Archer, C. L., and K. Caldeira, 2008: Historical trends in the jet streams. Geophys. Res. Lett., 35, L08803, doi:10.1029/ 2008 GL033614.

Bieda, S. W., C. L. Castro, S. L. Mullen, A. C. Comrie, and E. Pytlak, 2009: The relationship of transient upper-level troughs to variability of the North American monsoon system. J. Climate, 22, 4213-4227, doi:10.1175/2009JCLI2487.1.

Bosart, L., T. J. Melino, S. R. Sukup, E. S. Pytlak, J. E. Matusiak, S. J. Weiss, J. Racy, and R. S. Schneider, 2011: Potential vorticity disturbances as a trigger of southwest U.S. severe weather. 24th Conf. on Weather and Forecasting, Seattle, WA, Amer. Meteor. Soc., 11A.3. [Available online at https://ams. confex.com/ams/91Annual/webprogram/Paper181548.html.]

Carleton, A. M., 1987: Summer circulation climate of the American Southwest, 1945-1984. Ann. Assoc. Amer. Geogr., 77, 619634, doi:10.1111/j.1467-8306.1987.tb00184.x.

Castro, C. L., R. A. Pielke, and G. Leoncini, 2005: Dynamical downscaling: Assessment of value retained and added using the Regional Atmospheric Modeling System (RAMS). J. Geophys. Res., 110, D05108, doi:10.1029/ 2004JD004721.

,-- , and J. O. Adegoke, 2007a: Investigation of the summer climate of the contiguous United States and Mexico using the Regional Atmospheric Modeling System (RAMS). Part I: Model climatology (1950-2002). J. Climate, 20, 3844-3865, doi:10.1175/JCLI4211.1.

,,--- , S. D. Schubert, and P. J. Pegion, 2007b: Investigation of the summer climate of the contiguous United States and Mexico using the Regional Atmospheric Modeling System (RAMS). Part II: Model climate variability. J. Climate, 20, 3866-3887, doi:10.1175/JCLI4212.1.

— A. B. Beltrán-Przekurat, and R. A. Pielke Sr., 2009: Spatiotemporal variability of precipitation, modeled soil moisture, and vegetation greenness in North America within the recent observational record. J. Hydrometeor., 10, 1355-1378, doi:10.1175/ 2009JHM1123.1.

_, H.-I. Chang, F. Dominguez, C. Carrillo, J. Kyung-Schemm, and H. H.-M. Juang, 2012: Can a regional climate model improve warm season forecasts in North America? J. Climate, 25, 8212-8237, doi:10.1175/JCLI-D-11-00441.1.

,-- , T. Luong, T. Lahmers, M. Jares, and C. Carrillo, 2015: Projecting future changes in extreme weather during the North American monsoon in the Southwest with high resolution, convective-permitting regional atmospheric modeling. 29th Conf. on Hydrology, Phoenix, AZ, Amer. Meteor. Soc., 7.1. [Available online at https://ams.confex.com/ams/95Annual/webprogram/ Paper266692.html.]

Chang, H.-I., C. L. Castro, C. M. Carrillo, and F. Dominguez, 2015: The more extreme nature of U.S. warm season climate in the recent observational record and two "well-performing" dynamically downscaled CMIP3 models. J. Geophys. Res. Atmos., 120, 8244-8263, doi:10.1002/2015JD023333.

Corbosiero, K. L., M. J. Dickinson, and L. F. Bosart, 2009: The contribution of eastern North Pacific tropical cyclones to the rainfall climatology of the Southwest United States. Mon. Wea. Rev., 137, 2415-2435, doi:10.1175/2009MWR2768.1.

Douglas, A. V., and P. J. Englehart, 2007: A climatological perspective of transient synoptic features during NAME 2004. J. Climate, 20, 1947-1954, doi:10.1175/JCLI4095.1.

Douglas, M. W., R. A. Maddox, K. Howard, and S. Reyes, 1993: The Mexican monsoon. J. Climate, 6, 1665-1677, doi:10.1175/ 1520-0442(1993)006<1665:TMM > 2.0.CO;2.

Ebisuzaki, W., and R. Kistler, 2000: An examination of a dataconstrained assimilation. WCRP-109, WMO/TD-985, 14-17. [Available online at http://www.cpc.ncep.noaa.gov/products/ wesley/reanalysis2/wne_reanl_conf2.pdf.]

Finch, Z. O., and R. H. Johnson, 2010: Observational analysis of an upper-level inverted trough during the 2004 North American Monsoon Experiment. Mon. Wea. Rev., 138, 3540-3555, doi:10.1175/2010MWR3369.1.

Groisman, P. Ya., R. W. Knight, D. R. Easterling, T. R. Karl, G. C. Hegerl, and V. N. Razuvaev, 2005: Trends in intense 
precipitation in the climate record. J. Climate, 18, 1326-1350, doi:10.1175/JCLI3339.1.

Higgins, R. W., Y. Yao, and X. L. Wang, 1997: Influence of the North American monsoon system on the U.S. summer precipitation regime. J. Climate, 10, 2600-2622, doi:10.1175/ 1520-0442(1997)010<2600:IOTNAM > 2.0.CO;2.

Higgins, W., and Coauthors, 2006: The NAME 2004 field campaign and modeling strategy. Bull. Amer. Meteor. Soc., 87, 79-94, doi:10.1175/BAMS-87-1-79.

Hodges, K. I., 1995: Feature tracking on the unit sphere. Mon. Wea. Rev., 123, 3458-3465, doi:10.1175/1520-0493(1995)123<3458: FTOTUS $>2.0 . \mathrm{CO} ; 2$.

- 1996: Spherical nonparametric estimators applied to the UGAMP model integration for AMIP. Mon. Wea. Rev., 124, 2914-2932, doi:10.1175/1520-0493(1996)124<2914: SNEATT $>2.0 . \mathrm{CO} ; 2$.

— 1999: Adaptive constraints for feature tracking. Mon. Wea. Rev., 127, 1362-1373, doi:10.1175/1520-0493(1999)127<1362: ACFFT $>2.0 . \mathrm{CO} ; 2$.

Holton, J. R., 2004: An Introduction to Dynamic Meteorology. 4th ed. Elsevier Academic Press, 535 pp.

Hoskins, B. J., and K. I. Hodges, 2002: New perspectives on the Northern Hemisphere winter storm tracks. J. Atmos. Sci., 59, 1041-1061, doi:10.1175/1520-0469(2002)059<1041:NPOTNH > 2.0.CO;2.

Hsu, P., T. Li, J.-J. Luo, H. Murakami, A. Kitoh, and M. Zhao, 2012: Increase of global monsoon area and precipitation under global warming: A robust signal? Geophys. Res. Lett., 39, L06701, doi:10.1029/2012GL051037.

Hu, H., and F. Dominguez, 2015: Evaluation of oceanic and terrestrial sources of moisture for the North American monsoon using numerical models and precipitation stable isotopes. J. Hydrometeor., 16, 19-35, doi:10.1175/JHM-D-14-0073.1.

Janowiak, J. E., V. J. Dagostaro, V. E. Kousky, and R. J. Joyce, 2007: An examination of precipitation in observations and model forecasts during NAME with emphasis on the diurnal cycle. J. Climate, 20, 1680-1692, doi:10.1175/JCLI4084.1.

Jares, M., C. L. Castro, H.-I. Chang, C. Carrillo, J. J. Mazon, J. Stutler, and J. J. Brost, 2014: High resolution WRF simulation and climatological analysis of severe weather events during the North American monsoon. 26th Conf. on Weather Analysis and Forecasting/22nd Conf. on Numerical Weather Prediction, Atlanta, GA, Amer. Meteor. Soc., 151. [Available online at https://ams.confex.com/ams/94Annual/webprogram/ Paper237080.html.]

Kalnay, E., and Coauthors, 1996: The NCEP/NCAR 40-Year Reanalysis Project. Bull. Amer. Meteor. Soc., 77, 437-471, doi:10.1175/ 1520-0477(1996)077<0437:TNYRP $>2.0 . C O ; 2$.

Karl, T. R., and R. W. Knight, 1998: Secular trends in the precipitation amount, frequency, and intensity in the United States. Bull. Amer. Meteor. Soc., 79, 231-241, doi:10.1175/ 1520-0477(1998)079<0231:STOPAF $>2.0 . C O ; 2$.

Kelly, W. E., and D. R. Mock, 1982: A diagnostic study of upper tropospheric cold lows over the western North Pacific. Mon. Wea. Rev., 110, 471-480, doi:10.1175/1520-0493(1982)110<0471: ADSOUT $>2.0 . \mathrm{CO} ; 2$.

Landsea, C. W., and J. L. Franklin, 2013: Atlantic hurricane database uncertainty and presentation of a new database format. Mon. Wea. Rev., 141, 3576-3592, doi:10.1175/ MWR-D-12-00254.1.

Li, J., S. Sorooshian, W. Higgins, X. Gao, B. Imam, and K. Hsu, 2008: Influence of spatial resolution on diurnal variability during the North American monsoon. J. Climate, 21, 39673988, doi:10.1175/2008JCLI2022.1.
Livezey, R. E., and W. Y. Chen, 1983: Statistical field significance and its determination by Monte Carlo techniques. Mon. Wea. Rev., 111, 46-59, doi:10.1175/1520-0493(1983)111<0046: SFSAID $>2.0 . \mathrm{CO} ; 2$.

Lu, E., X. Zeng, Z. Jiang, Y. Wang, and Q. Zhang, 2009: Precipitation and precipitable water: Their temporal-spatial behaviors and use in determining monsoon onset/retreat and monsoon regions. J. Geophys. Res., 114, D23105, doi:10.1029/ 2009JD012146.

Lu, J., G. A. Vecchi, and T. Reichler, 2007: Expansion of the Hadley cell under global warming. Geophys. Res. Lett., 34, L06805, doi:10.1029/2006GL028443.

Maddox, R. A., D. M. McCollum, and K. W. Howard, 1995: Largescale patterns associated with severe summertime thunderstorms over central Arizona. Wea. Forecasting, 10, 763-778, doi:10.1175/1520-0434(1995)010<0763:LSPAWS>2.0.CO;2.

McCollum, D. M., R. A. Maddox, and K. W. Howard, 1995: Case study of a severe mesoscale convective system in central Arizona. Wea. Forecasting, 10, 643-665, doi:10.1175/ 1520-0434(1995)010<0643:CSOASM >2.0.CO;2.

Meehl, G. A., F. Zwiers, J. Evans, T. Knutson, L. Mearns, and P. Whetton, 2000: Trends in extreme weather and climate events: Issues related to modeling extremes in projections of future climate change. Bull. Amer. Meteor. Soc., 81, 427-436, doi:10.1175/1520-0477(2000)081<0427:TIEWAC >2.3.CO;2.

Miguez-Macho, G., G. L. Stenchikov, and A. Robock, 2005: Regional climate simulations over North America: Interaction of local processes with improved large-scale flow. J. Climate, 18, 1227-1246, doi:10.1175/JCLI3369.1.

Min, S.-K., X. Zhang, F. W. Zwiers, and G. C. Hegerl, 2011: Human contribution to more-intense precipitation extremes. Nature, 470, 378-381, doi:10.1038/nature09763.

Moncrieff, M., and M. Miller, 1976: The dynamics and simulation of tropical cumulonimbus and squall lines. Quart. J. Roy. Meteor. Soc., 102, 373-394, doi:10.1002/qj.49710243208.

Muller, C. J., L. E. Back, and P. A. O'Gorman, 2011: Intensification of precipitation extremes with warming in a cloud-resolving model. J. Climate, 24, 2784-2800, doi:10.1175/2011JCLI3876.1.

Newman, A., and R. H. Johnson, 2012: Mechanisms for precipitation enhancement in a North American monsoon uppertropospheric trough. J. Atmos. Sci., 69, 1775-1792, doi:10.1175/ JAS-D-11-0223.1.

O'Gorman, P. A., 2012: Sensitivity of tropical precipitation extremes to climate change. Nat. Geosci., 5, 697-700, doi:10.1038/ ngeo1568.

Pytlak, E., 2006: Revisiting upper tropospheric lows and their interaction with the North American monsoon: What is next in hypothesis formulation and testing? Proc. National Weather Association 31st Annual Meeting, Cleveland, OH, National Weather Association. [Available online at http://www.nwas.org/ meetings/nwa2006/index.php.]

, M. Goering, and A. Bennett, 2005: Upper-tropospheric troughs and their interaction with the North American monsoon. Preprints, 19th Conf. on Hydrology, San Diego, CA, Amer. Meteor. Soc., JP2.3. [Available online at https://ams.confex.com/ams/ pdfpapers/85393.pdf.]

Ritchie, E. A., K. M. Wood, D. S. Gutzler, and S. R. White, 2011: The influence of eastern Pacific tropical cyclone remnants on the southwestern United States. Mon. Wea. Rev., 139, 192210, doi:10.1175/2010MWR3389.1.

Rockel, B., C. L. Castro, R. A. Pielke Sr., H. von Storch, and G. Leoncini, 2008: Dynamical downscaling: Assessment of model system dependent retained and added variability for 
two different regional climate models. J. Geophys. Res., 113, D21107, doi:10.1029/2007JD009461.

Schiffer, N. J., and S. W. Nesbitt, 2012: Flow, moisture, and thermodynamic variability associated with Gulf of California surges within the North American monsoon. J. Climate, 25, 4220-4241, doi:10.1175/JCLI-D-11-00266.1.

Seastrand, S., Y. Serra, C. L. Castro, and E. Ritchie, 2015: The dominant synoptic-scale modes of North American monsoon precipitation. Int. J. Climatol., 35, 2019-2032, doi:10.1002/joc.4104.

Seidel, D. J., Q. Fu, W. J. Randel, and T. J. Reichler, 2008: Widening of the tropical belt in a changing climate. Nat. Geosci., 1, 21-24, doi:10.1038/ngeo.2007.38.

Serra, Y. L., G. N. Kiladis, and K. I. Hodges, 2010: Tracking and mean structure of easterly waves over the Intra-Americas Sea. J. Climate, 23, 4823-4840, doi:10.1175/2010JCLI3223.1.

Skamarock, W. C., and Coauthors, 2008: A description of the Advanced Research WRF version 3. NCAR Tech Note
NCAR-TN-475+STR, 113 pp. [Available online at http:// www2.mmm.ucar.edu/wrf/users/docs/arw_v3.pdf.]

Thorncroft, C., and K. Hodges, 2001: African easterly wave variability and its relationship to Atlantic tropical cyclone activity. J. Climate, 14, 1166-1179, doi:10.1175/1520-0442(2001)014<1166: AEWVAI $>2.0 . \mathrm{CO} ; 2$.

von Storch, H., H. Langenberg, and F. Feser, 2000: A spectral nudging technique for dynamical downscaling purposes. Mon Wea. Rev., 128, 3664-3673, doi:10.1175/1520-0493(2000)128<3664: ASNTFD $>2.0 . \mathrm{CO} ; 2$

Whitfield, M. B., and S. W. Lyons, 1992: An upper-tropospheric low over Texas during summer. Wea. Forecasting, 7, 89-106, doi:10.1175/1520-0434(1992)007<0089:AUTLOT>2.0.CO;2.

Wood, K. M., and E. A. Ritchie, 2013: An updated climatology of tropical cyclone impacts on the southwestern United States. Mon. Wea. Rev., 141, 4322-4336, doi:10.1175/ MWR-D-13-00078.1. 